\title{
Numerical Study of Damage to Rock Surrounding an Underground Coal Roadway Excavation
}

\author{
Jiangbo Wei, ${ }^{1,2,3}$ Shuangming Wang $\mathbb{D}^{1,2,3}{\text { Zhou Zhao } \mathbb{D}^{1},{ }^{1,3} \text { Delu Li, }}^{1,2,3}$ and Lipeng Guo ${ }^{1,4}$ \\ ${ }^{1}$ College of Geology and Environment, Xi'an University of Science and Technology, Xi'an, Shaanxi 710054, China \\ ${ }^{2}$ Geological Research Institute for Coal Green Mining, Xi'an University of Science and Technology, Xi'an, Shaanxi 710054, China \\ ${ }^{3}$ Shaanxi Provincial Key Laboratory of Geological Support for Coal Green Exploitation, \\ Xi'an University of Science and Technology, Xi'an, Shaanxi 710054, China \\ ${ }^{4}$ Shenmu County Xiangshuihe Mining Co. Ltd., Yulin, Shaanxi 719300, China
}

Correspondence should be addressed to Shuangming Wang; mtlskcdzyjy@163.com and Zhou Zhao; zhaozhou@xust.edu.cn

Received 8 July 2020; Revised 18 August 2020; Accepted 23 August 2020; Published 10 September 2020

Academic Editor: Fengqiang Gong

Copyright (c) 2020 Jiangbo Wei et al. This is an open access article distributed under the Creative Commons Attribution License, which permits unrestricted use, distribution, and reproduction in any medium, provided the original work is properly cited.

In coal mines, underground roadways are required to transport coal and personnel. Such tunnels can become unstable and hazardous. This study simulates deformation and damage in the rock surrounding a shallow coal seam roadway using particle flow code. A numerical model of particle flow in the surrounding rock was constructed based on field survey and drilling data. Microcharacteristic indices, including stress, displacement, and microcrack fields, were used to study deformation and damage characteristics and mechanisms in the surrounding rocks. The results show that the stress within the rock changed gradually from a vertical stress to a circumferential stress pattern. Stress release led to self-stabilizing diamond-shaped and X-shaped tensile stress distribution patterns after the excavation of the roadway. Cracking increased and eventually formed cut-through cracks as the concentrated stress transferred to greater depths at the sides, forming shear and triangular-shaped failure regions. Overall, the roof and floor were relatively stable, whereas the sidewalls gradually failed. These results provide a reference for the control of rock surrounding roadways in coal mines.

\section{Introduction}

Increasing population growth and socioeconomic development have led to increases in the extent and depth of coal mining [1]. This has led to an increase in engineering safety problems such as mineshaft roof instability, roof and floor water inrush, gas outbursts, and deformation of the rocks surrounding roadways [2-8]. These problems influence the safety, environmental impacts, and efficiency of coal extraction. The stability of rocks surrounding underground coal roadways and associated stability control technology has become the focus of mining production and safety research [9-11]. Coal roadways are the main passages used for underground transportation; therefore, their stability affects the ease and safety of coal and personnel transport. As coal roadways are excavated, their roof, bottom plate, and sides can become deformed and damaged due to excavation- mediated unloading, which affects the safety of the mineshaft. Therefore, it is necessary to study deformation/damage mechanisms and characteristics in the rock surrounding coal roadways after excavation.

Many studies have examined the characteristics and control of rock surrounding coal mine roadways. Various research methods have been used, including field investigation, theoretical calculation and analysis, and laboratory tests, and good results have been achieved [12-16]. Li et al. [17] used a large-scale geomechanical model to investigate the deformation and displacement characteristics and the stress evolution of rock surrounding a deep roadway within the Zhaolou Coal Mine, Juye Mining Area, China. Xue et al. [18] used theoretical analysis to model the stress and strain of rock surrounding a roadway and combined it with equations describing gas seepage. A hydraulic model of roadway-surrounding rock for different areas was established. The 


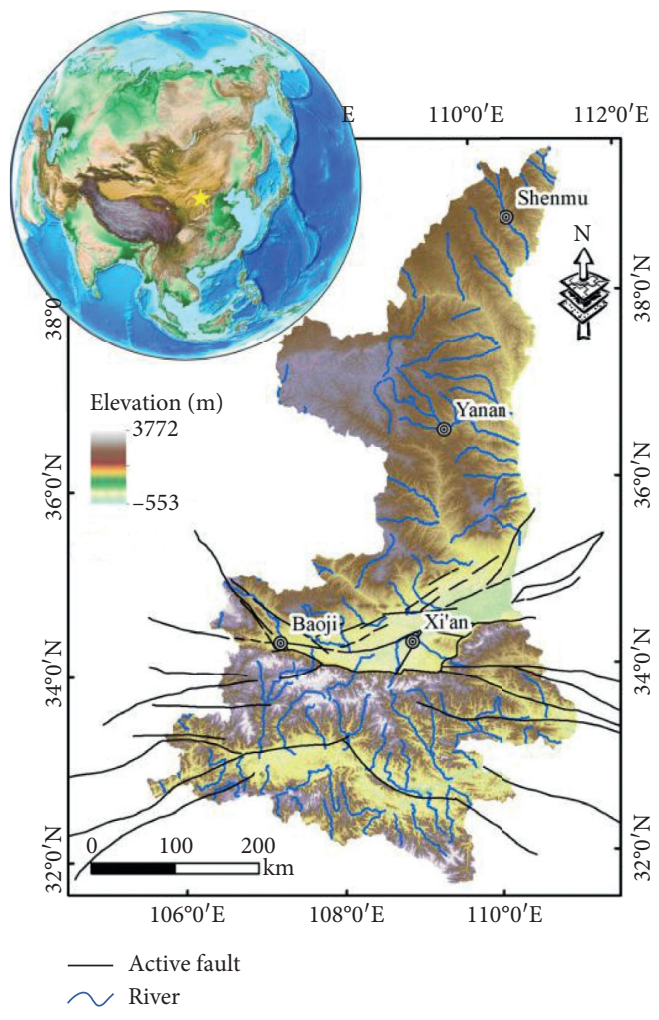

(a)

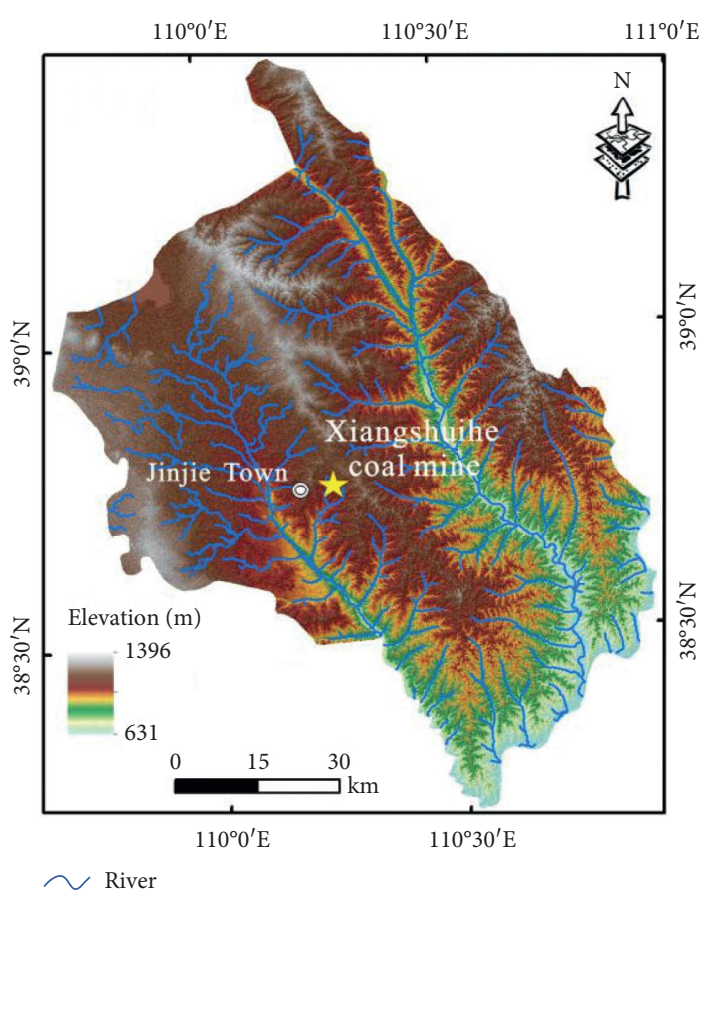

(b)

Figure 1: (a) Location of Shenmu city, Shaanxi Province, China. (b) Digital elevation model showing Shenmu city and Xiangshuihe Coal Mine.

permeability characteristics and pressure distribution of rock in the excavation-damaged area were studied. With developments in computer technology, numerical simulation has become a popular research method that has been applied to coal mining research [19-23]. Simulations of roadway stability and surrounding rock deformation have been undertaken based on the finite element method (FEM) and finite difference method (FDM) [24-28]. Yu et al. [29] performed a theoretical analysis of a soft-rock roadway in inclined strata at the Meihe Mine, China, using FLAC3D simulation software. The deformation and failure mechanisms of surrounding rock were analyzed, and measures to improve its stability were discussed. Yang et al. [30] used FLAC3D to simulate and analyze the complex process of stress and displacement during coal roadway driving under various initial stress conditions and provided a theoretical basis for the control of outburst accidents. The FEM and FDM are suitable for simulating small deformations in continuous media but have some disadvantages in modeling high deformation/damage characteristics in discontinuous media. Discrete element theory can better simulate discontinuous high deformation in rock and soil, especially that related to the process of deformation damage in roadway-surrounding rock [31-35]. Yang et al. [36] combined field investigations, laboratory experiments, and universal distinct element code (UDEC) simulations to investigate the deformation and failure of rock surrounding a deep, soft-rock roadway in the Xin'an Coal
Mine, Gansu province, China. Gao and Stead [37] simulated and analyzed the evolution of cracks during the deformation and failure of rock surrounding a roadway excavation in a coalmine at high horizontal stresses using PFC3D and 3DEC discrete element software. Scholars have also studied the deformation characteristics of rocks surrounding excavated rectangular caverns (tunnels) by theoretical calculation and laboratory experiments. They have revealed the mechanism by which the spalling phenomenon forms in the sidewalls of rectangular caverns [38-40]. Currently, deformation/damage mechanisms, stability analysis, and deformation control in roadway-surrounding rock have mainly been simulated using the finite element, finite difference, and block discrete element methods. The particle flow discrete element method has also been used to simulate the deformation/damage characteristics of overlying rock in coal mine goafs [41, 42], confirming that this method can be applied to underground excavations. However, there are relatively few studies that have used the microcharacteristics of stress, microcracks, and porosity to investigate deformation and failure in roadway-surrounding rock. Thus, detailed quantitative analyses of microscopic deformation characteristics are required to better understand the influences on stability, deformation, and damage to rock surrounding coal roadways.

In the present study, a shallow coal seam roadway in the Xiangshuihe Coal Mine, Northern Shaanxi, China, was used as a case study. Based on a field survey of the geological 


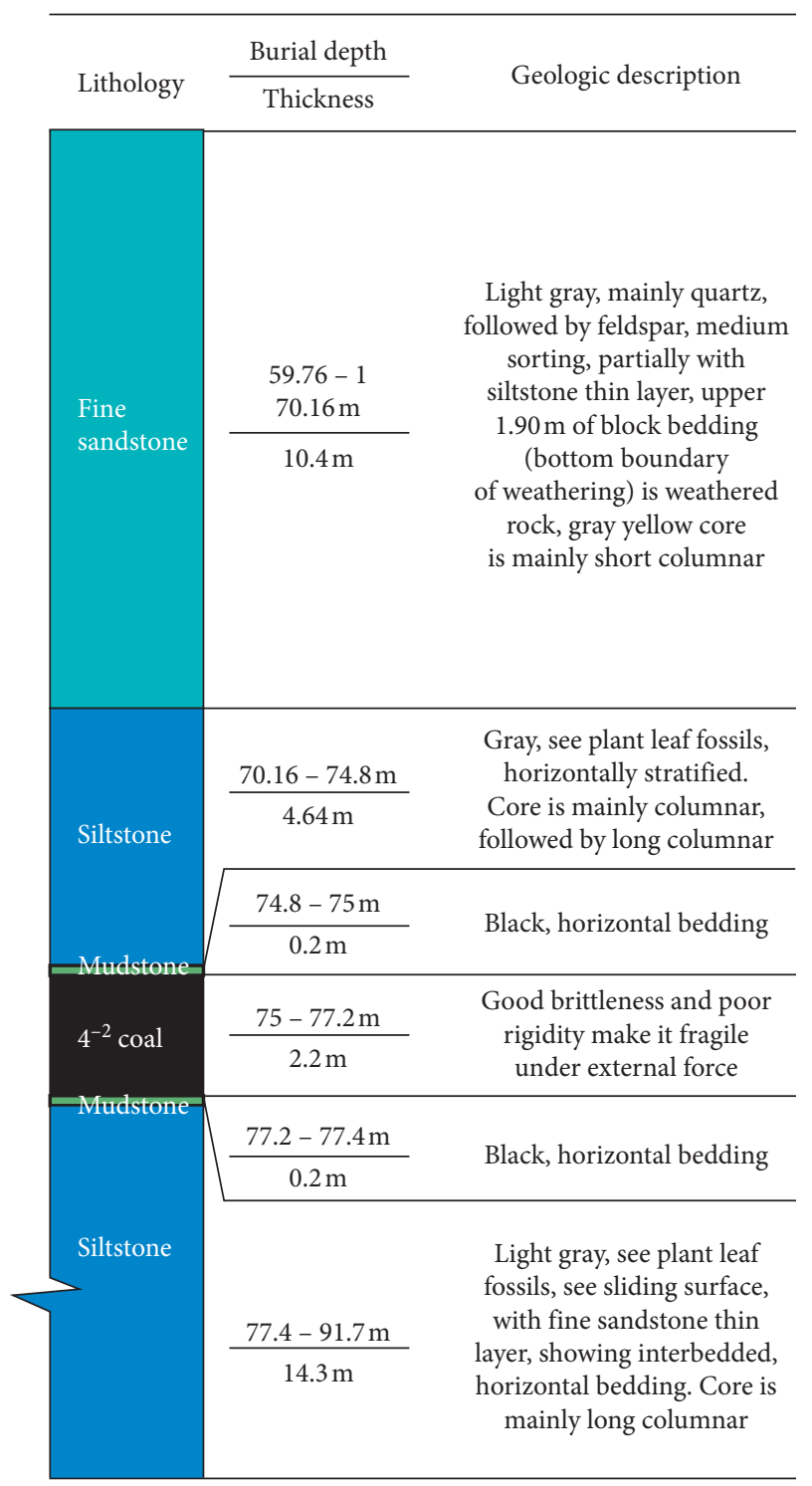

FIGURE 2: Stratigraphic column and geological descriptions of the rocks surrounding the 4-2 coal seam.

environment, a numerical model of the coal roadway was constructed using particle flow code (PFC). The deformation/damage characteristics and stability of the surrounding rock after roadway excavation were simulated and analyzed. The present study provides a theoretical basis for surrounding rock stability analysis, which will inform coal roadway design and the prevention of dynamic roadway disasters. Additionally, this study provides supplementary insights into the construction of shallow coal seam roadways in western China in terms of safety, yields, efficiency, and environmental impacts.

\section{Description of the Study Site}

The Xiangshuihe Coal Mine is located approximately $16 \mathrm{~km}$ southwest of Shenmu County, Shaanxi province, China (Figure 1(a)). It is part of the Yushen Mining Area, which is located within the Jurassic coalfields of northern Shaanxi,
China. The mine is located at $38^{\circ} 43^{\prime} 00^{\prime \prime}-38^{\circ} 48^{\prime} 30^{\prime \prime} \mathrm{N}$, $110^{\circ} 13^{\prime} 30^{\prime \prime}-110^{\circ} 21^{\prime} 45^{\prime \prime} \mathrm{E}$ (Figure 1(b)), which is on the border between the northern end of the Loess Plateau and the southeastern margin of the Maowusu Desert. The topography is high in the middle and relatively low in the south and north with elevations of 1125.50-1314.80 m. The surfaces of the central and northern parts of the area are dominated by wind-eroded eolian dune landforms, while the southern and northeastern surfaces are dominated by hilly loess landforms.

The principal strata in the area are 4-2 coal seams, mudstones, and sandstones of the Middle Jurassic Yan'an Formation; clay of the Paleogene-Neogene Baode Formation; subclay and subsandy soils of the mid-Pleistocene Lishi Formation; middle, fine, and silty sands of the upper Pleistocene Salawusu Formation; and silty sands of the Holocene eolian sand and alluvium. The lithologies within the roof of the 4-2 coal seam of the Yan'an formation are mudstone, siltstone, and fine sandstone, and the floor consists of mudstone and siltstone (Figure 2).

Based on the field geological survey, the actual roadway section size is $5.4 \times 2.6 \mathrm{~m}$. The roof of the roadway is supported by a combination of anchor cables and mesh, the floor is not reinforced, the sides are unsupported, and coal rock spalling occurs locally (Figure 3 ).

\section{Numerical Model and the Particle Flow Code}

3.1. PFC Method. The particle flow code (PFC) method uses discrete element methods [43]. The rock-soil mass is simulated as a series of rigid disks (or spheres in $3 \mathrm{D}$ code) with specific mechanical properties. These represent particles according to a specific contact model, and the macromechanical properties of the rock-soil mass are simulated via the movement of, and interactions between, the particles [44]. The interparticle interactions and particle motion are simulated using Newton's law of motion and the law of force-displacement. The latter is used to iteratively calculate the particle-particle and particle-boundary contact forces and torques. Newton's law of motion is used to update the motion and rotation of particles $[45,46]$. The calculations alternate between the application of Newton's law and the law of force-displacement until the model approaches an equilibrium state. Thus, the particle flow calculations are dynamic equilibrium calculations [47]. The models of interparticle contact include a linear contact model (LM), linear contact bonding model (CBM), and linear parallel bond model (PBM). The LM is most suitable for loosely consolidated materials, such as coarse sand. The CBM is most suitable for materials formed of particles that contact at points without significant interparticle torque, such as loess. The PBM is most suitable for brittle bodies with higher strengths than those described by LM and CBM. This model incorporates interparticle torque action and is suitable for consolidated rock masses. Therefore, the PBM was selected in the present study to model the surrounding rock mass of a roadway (Figure 4). During the initial stage of model construction, the rock mass was assigned to a specific PBM. After the application of external forces 


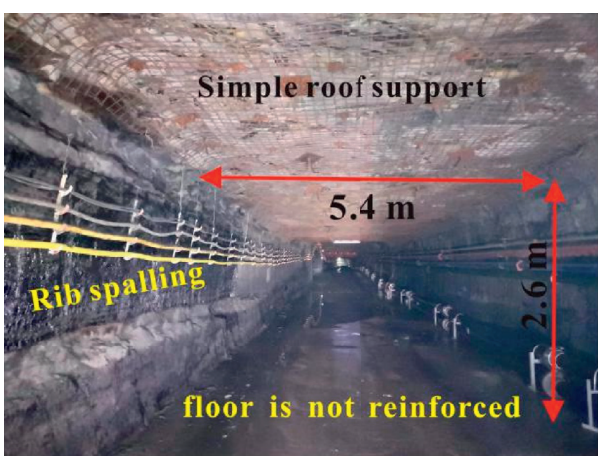

(a)

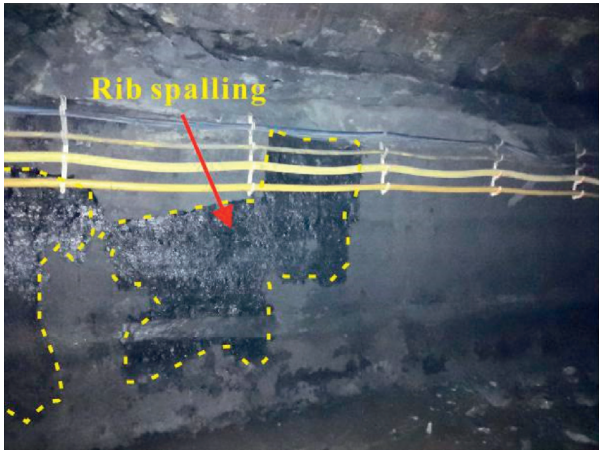

(c)

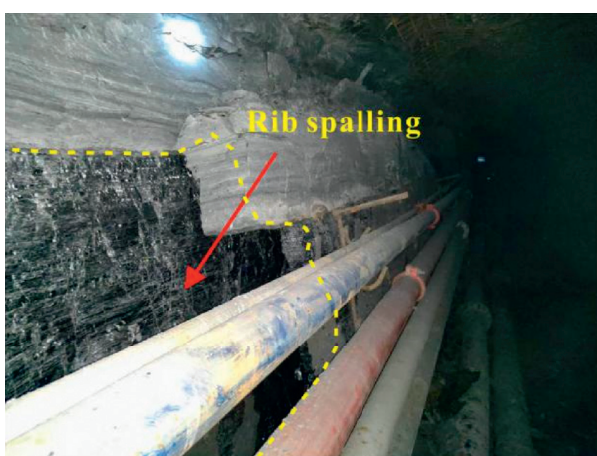

(b)

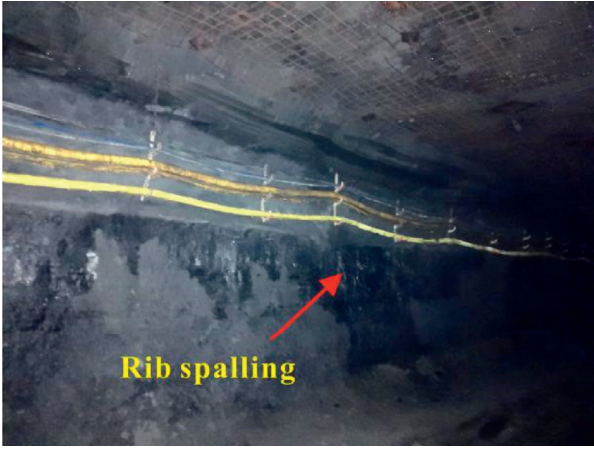

(d)

FigURE 3: Roadway size and failure characteristics of the surrounding rock.
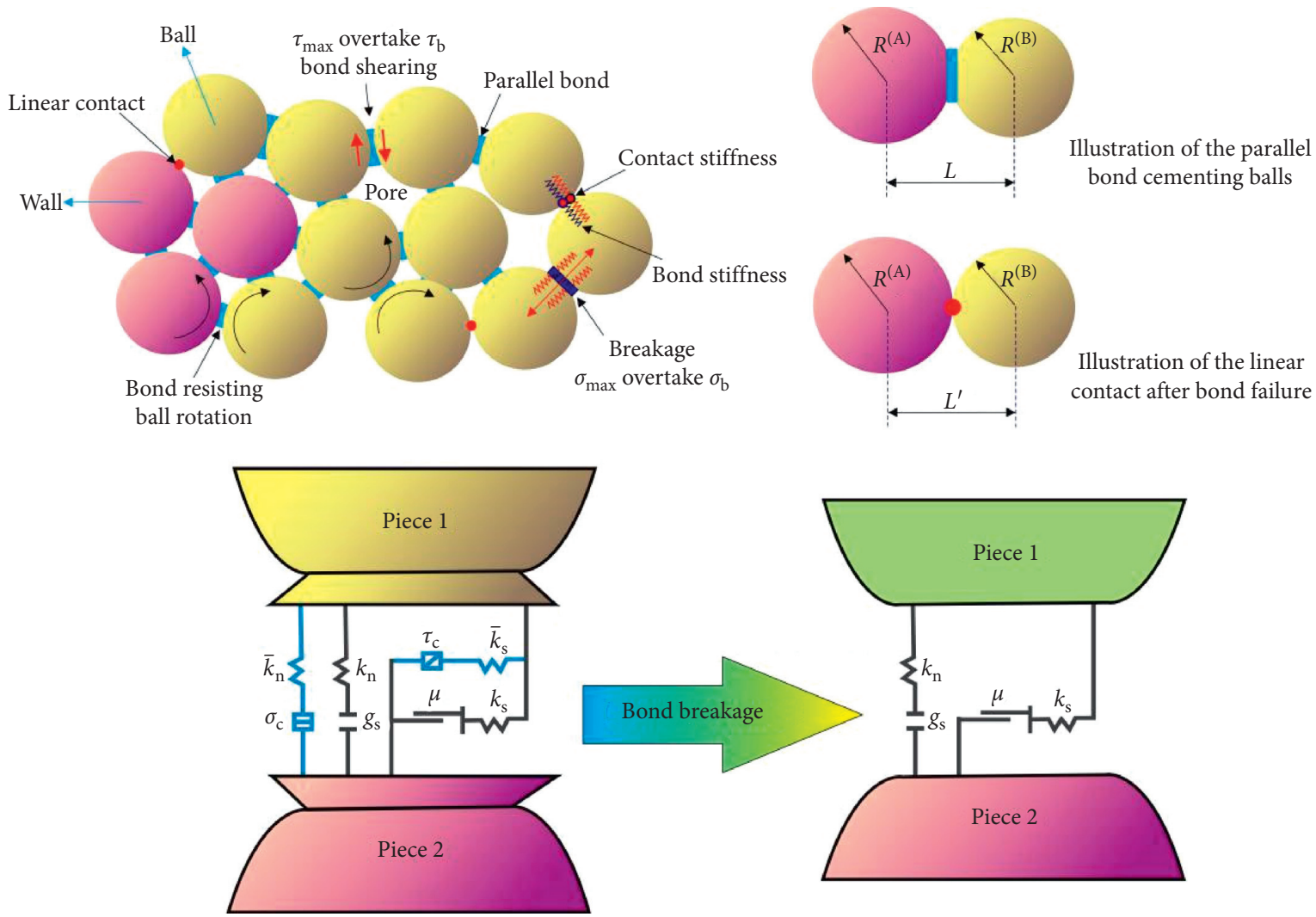

— Linear element

— Parallel-bond element

Figure 4: Illustration of the parallel bond model (PBM). 


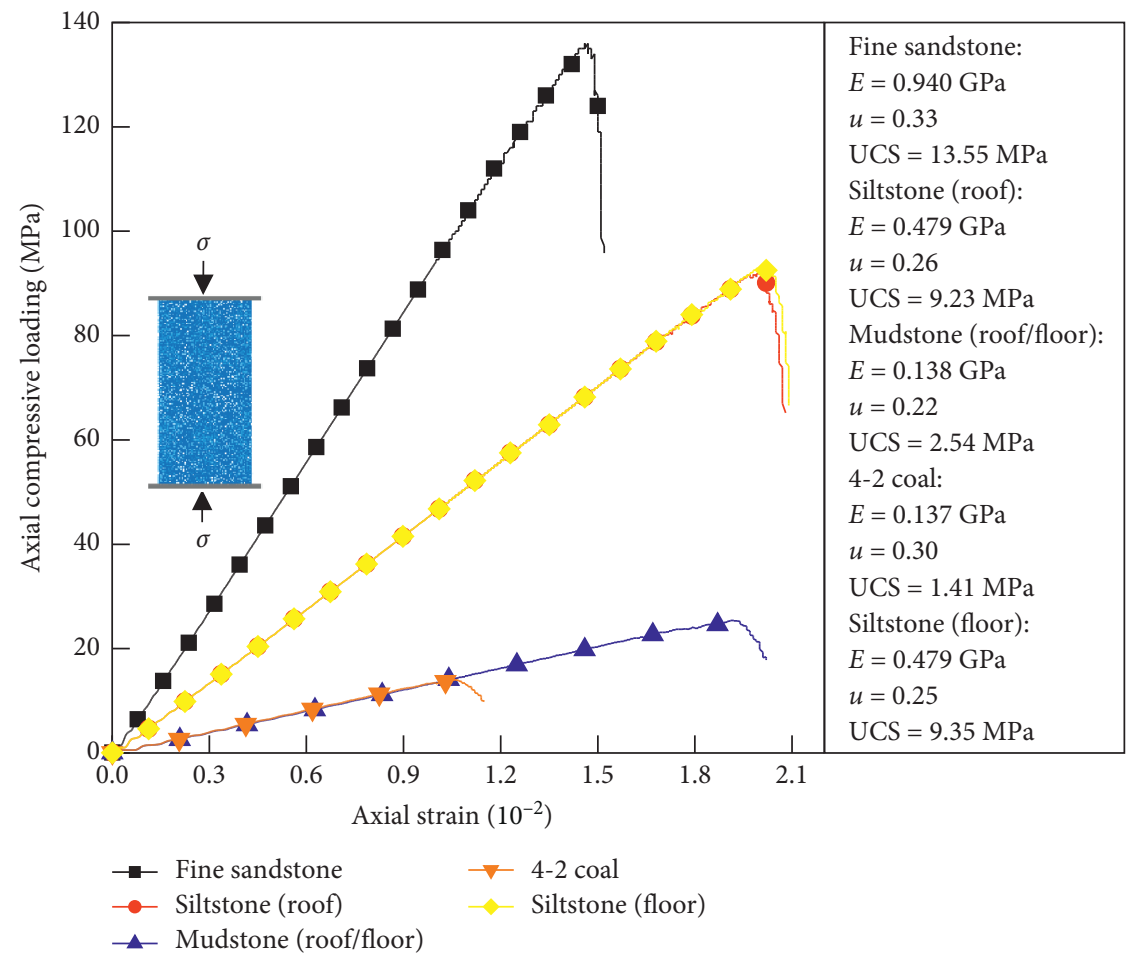

FIGURE 5: Calibration curve of strength parameters of each rock mass.
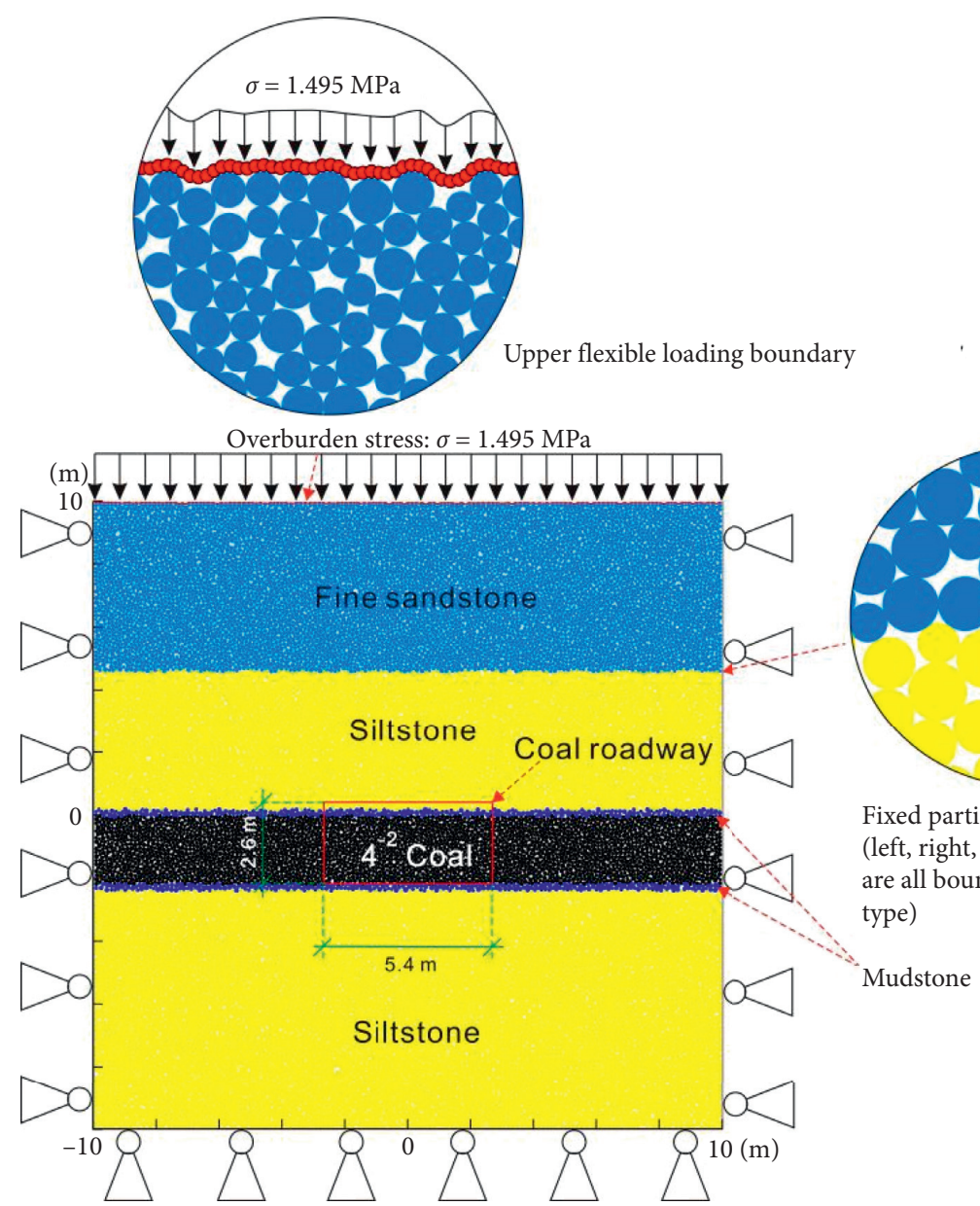

FIGURE 6: Cross-section of the model of rock surrounding the coal roadway, with insets showing magnified views of critical areas. 
TABLE 1: Calculated macrostrength parameters of intact rock and rock mass.

\begin{tabular}{lccccc}
\hline \multirow{2}{*}{ Lithology } & \multicolumn{2}{c}{ Intact rock } & \multirow{2}{*}{ RQD } & \multicolumn{2}{c}{ Rock mass } \\
& $E_{\mathrm{r}}(\mathrm{GPa})$ & $\mathrm{UCS}_{\mathrm{r}}(\mathrm{MPa})$ & 65.50 & 0.94 & $\mathrm{UCS}(\mathrm{MPa})$ \\
\hline Fine sandstone & 4.6 & 41.37 & 56.87 & 0.48 & 9.57 \\
Siltstone (roof) & 3.4 & 36.50 & 42.72 & 0.14 & 2.53 \\
Mudstone (roof) & 1.8 & 15.30 & 36.06 & 0.14 & 1.40 \\
$4-2$ coal & 2.4 & 10.30 & 42.72 & 0.14 & 2.53 \\
Mudstone (floor) & 1.8 & 15.30 & 57.00 & 0.48 & 9.35 \\
Siltstone (floor) & 3.4 & 36.80 & & & \\
\hline
\end{tabular}
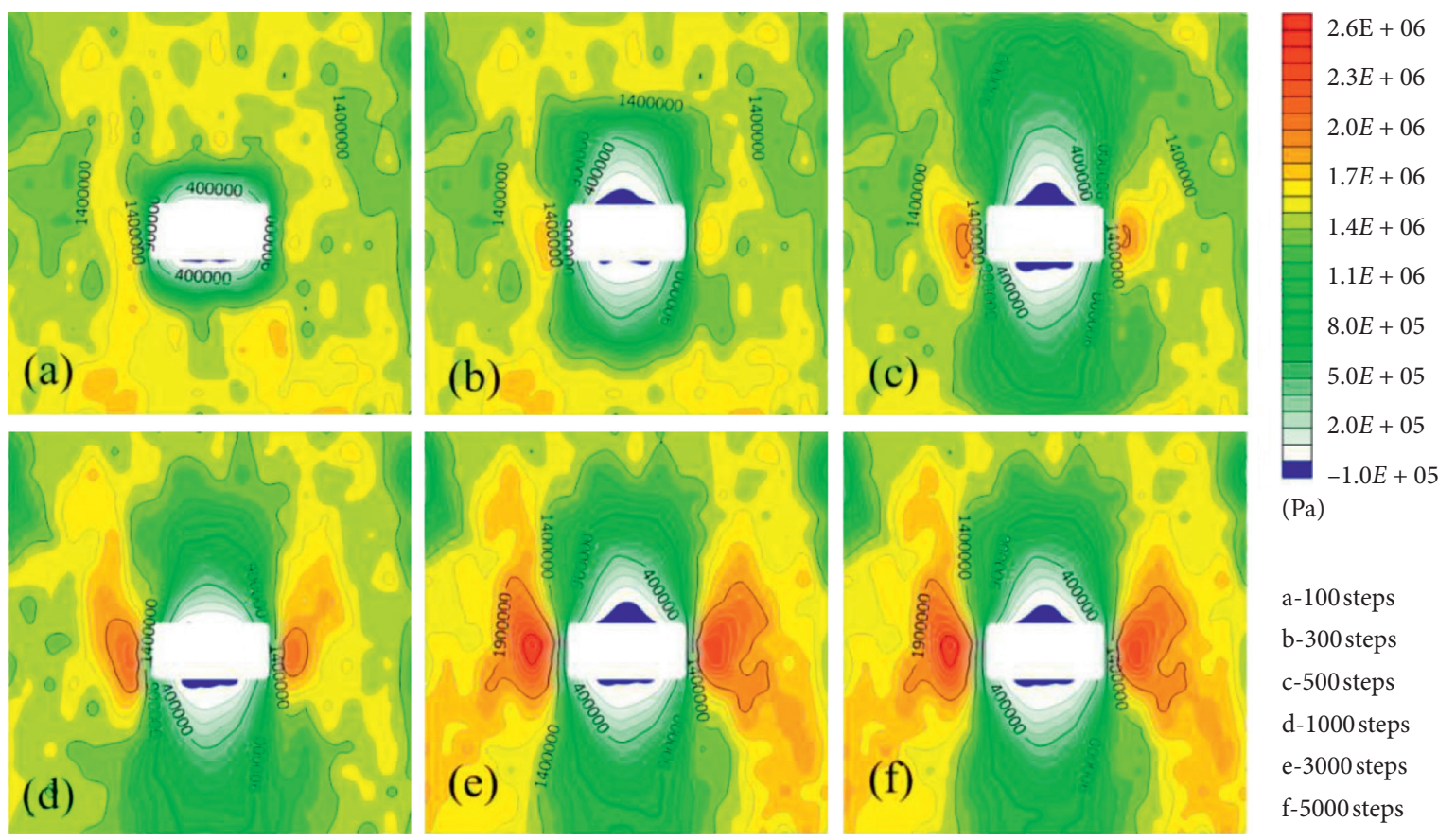

FIgURE 7: Vertical stress nephogram: (a) 100 steps, (b) 300 steps, (c) 500 steps, (d) 1000 steps, (e) 3000 steps, and (f) 5000 steps.

TABLE 2: The macro-micro parameter calibration for the strength parameters of the different lithologies.

\begin{tabular}{|c|c|c|c|c|c|c|c|c|}
\hline \multirow{2}{*}{ Lithology } & \multicolumn{3}{|c|}{ Macrostrength parameter } & \multicolumn{5}{|c|}{ Microstrength parameter } \\
\hline & $E(\mathrm{GPa})$ & $\mu$ & UCS (MPa) & $E_{\mathrm{b}}(\mathrm{GPa})$ & $E_{\mathrm{c}}(\mathrm{GPa})$ & $k^{*}$ & $\tau_{\mathrm{c}}(\mathrm{MPa})$ & $\sigma_{c}(\mathrm{MPa})$ \\
\hline Fine sandstone & 0.94 & 0.32 & 13.57 & 0.650 & 0.650 & 2.75 & 7.90 & 7.90 \\
\hline Siltstone (roof) & 0.48 & 0.26 & 9.24 & 0.320 & 0.320 & 2.23 & 5.50 & 5.50 \\
\hline Mudstone (roof) & 0.14 & 0.22 & 2.53 & 0.093 & 0.093 & 1.89 & 1.53 & 1.53 \\
\hline $4^{-2} \mathrm{coal}$ & 0.14 & 0.29 & 1.40 & 0.095 & 0.095 & 2.49 & 0.79 & 0.79 \\
\hline Mudstone (floor) & 0.14 & 0.22 & 2.53 & 0.093 & 0.093 & 1.89 & 1.53 & 1.53 \\
\hline Siltstone (floor) & 0.48 & 0.26 & 9.35 & 0.320 & 0.320 & 2.23 & 5.57 & 5.57 \\
\hline
\end{tabular}

$E$ is Young's modulus; $\mu$ is Poisson's ratio; UCS is the unconfined compressive strength; $E_{\mathrm{b}}$ is the bond effective modulus; $E_{\mathrm{c}}$ is the contact effective modulus; $k^{*}$ is the normal-shear stiffness ratio; $\tau_{\mathrm{c}}$ is the shear bond strength; $\sigma_{\mathrm{c}}$ is the tensile bond strength.

(loading or unloading), the interparticle contact stresses and particle motions were updated until the rock reached an equilibrium state. If the interparticle contact stress was greater than the interparticle bond strength, then the bonds were considered to be destroyed, and the contact model was reassigned as an LM.
3.2. Calculation of Microstrength Parameters. The rock mass was considered to be a combination of rock and structural planes. The strength parameters of the rock mass were calculated in combination with its rock quality designation (RQD). The rock strength parameters were measured in laboratory experiments on drilled rock samples, and the 


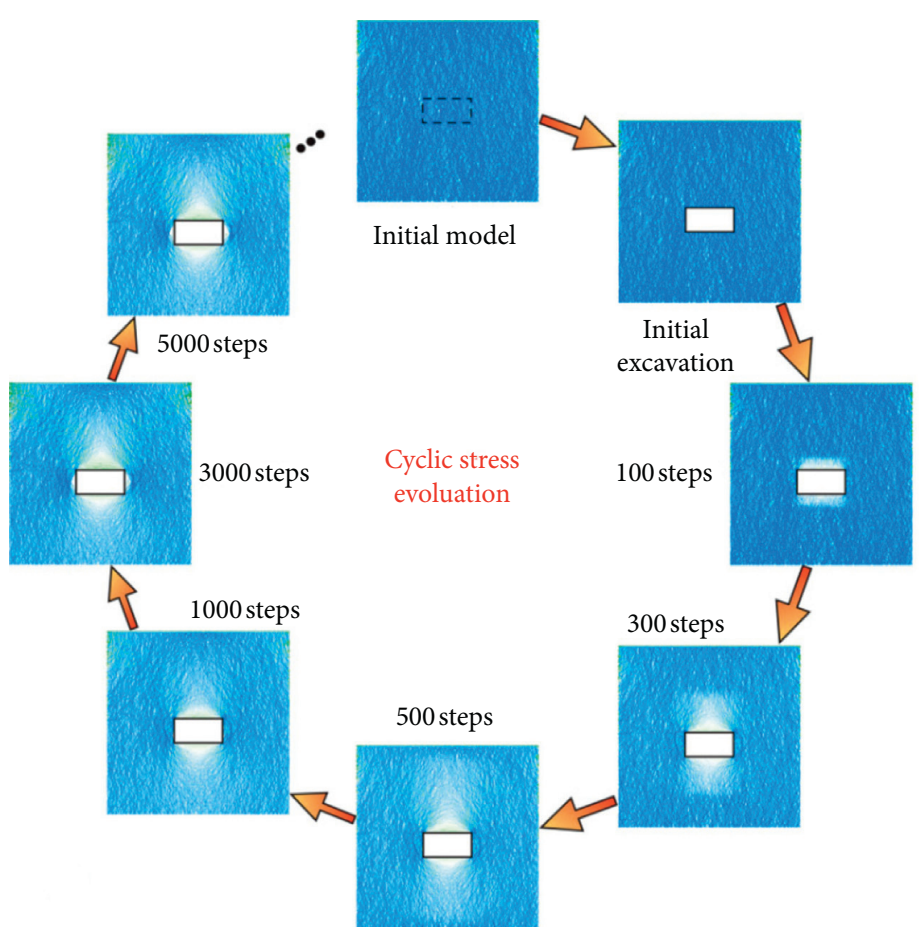

(a)

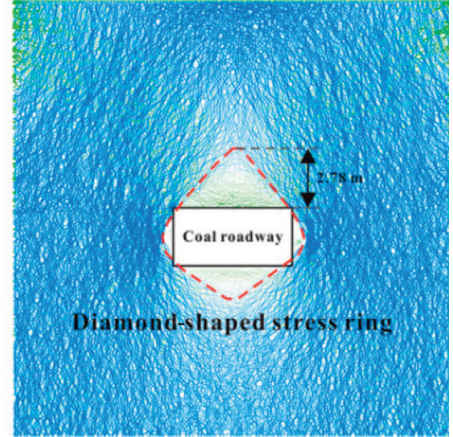

(b)

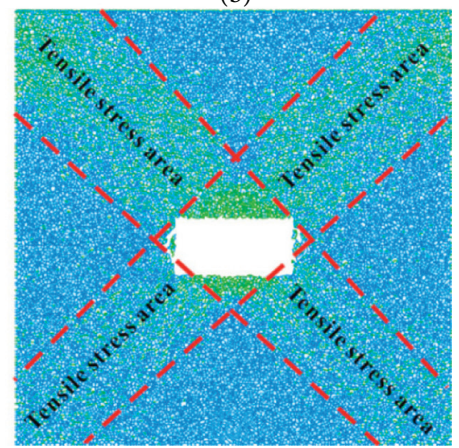

(c)

Figure 8: Characteristics of contact forces. (a) The evolution of contact forces. (b) Diamond pattern of contact forces after excavation. (c) Xshaped tensile stress pattern after excavation. The contact forces were greater where the short line of contact force was wider in (a) and (b) and vice versa. (c) The tensile stress and compressive stress are shown as short lines of the same width to show the X-shaped tensile stress zone (blue represents compressive stress and green represents tensile stress).

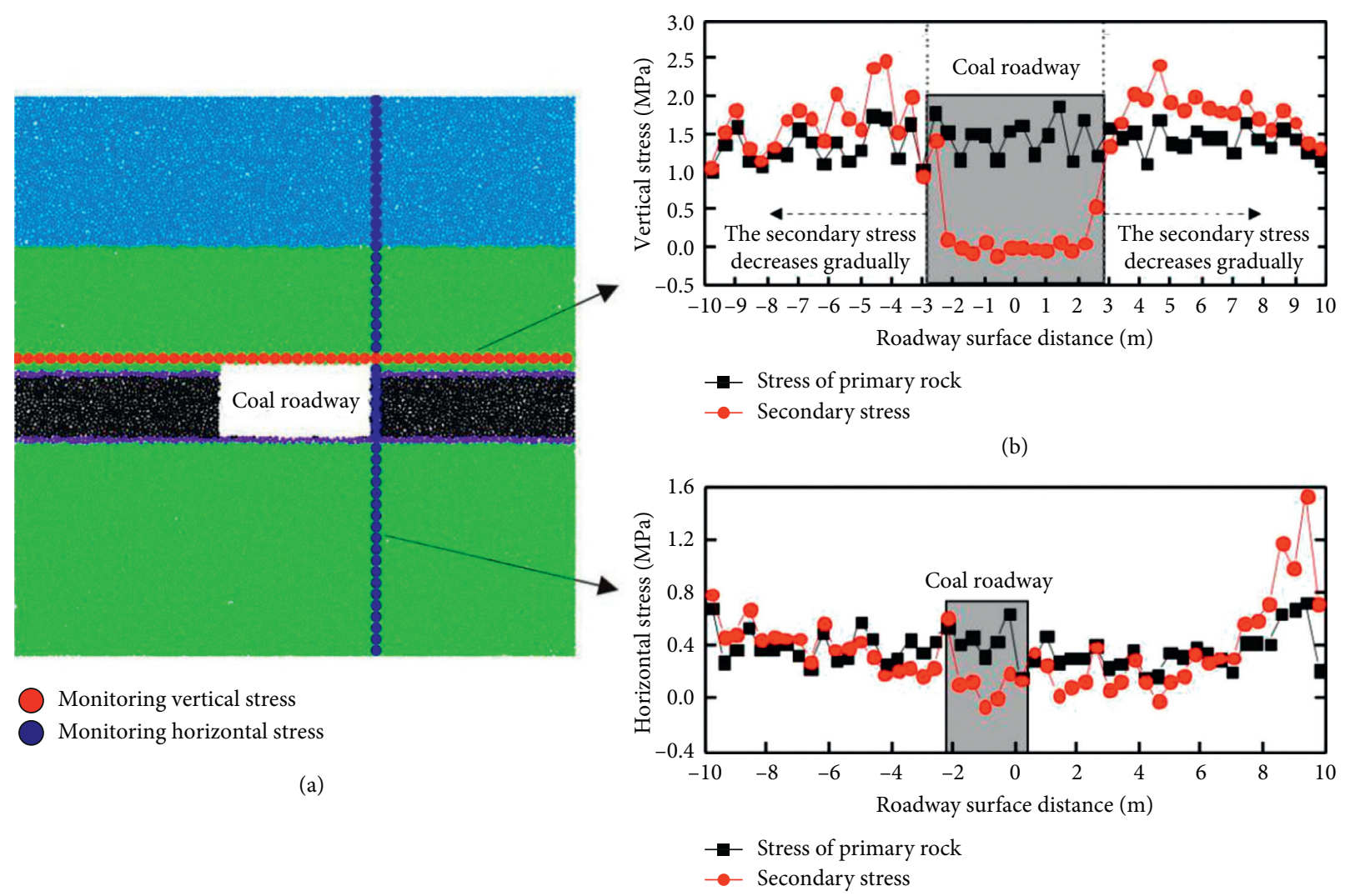

(c)

FIGURE 9: Monitoring of the roadway-surrounding rock. 


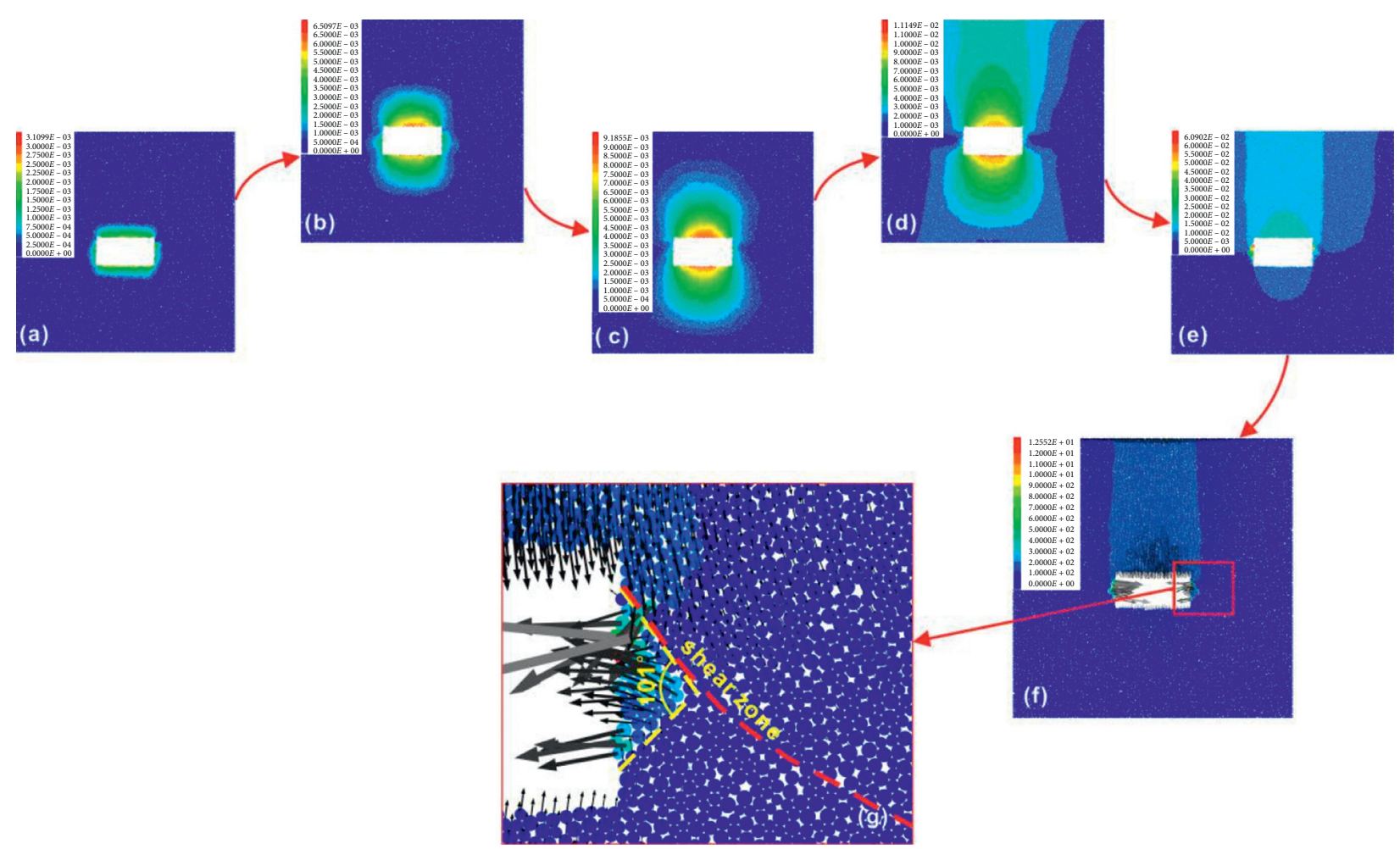

FIGURE 10: Evolution of displacement. (a) 100-step displacement cloud chart; (b) 300-step displacement cloud chart; (c) 500-step displacement cloud chart; (d) 1000-step displacement cloud chart; (e) 3000-step displacement cloud chart; (f) 5000-step displacement cloud chart and the displacement vector; (g) local enlargement of 5000-step displacement cloud chart and the displacement vector.

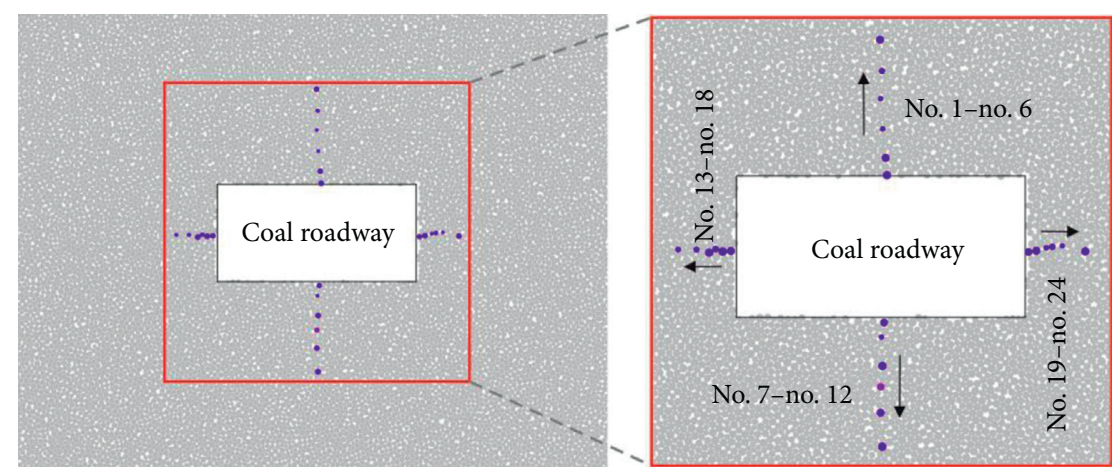

FIGURE 11: Inspection point locations in the rock surrounding the coal roadway.

RQD was calculated from their characteristics (Table 1). Young's modulus of the rock mass was calculated using the following equation [48]:

$$
\frac{E_{\mathrm{m}}}{E_{\mathrm{r}}}=10^{0.0186 \mathrm{RQD}-1.91} \text {, }
$$

where $E_{\mathrm{r}}$ and $E_{\mathrm{m}}$ are Young's moduli of intact rock and the rock mass, respectively, and RQD is the rock mass quality index.

The strength of the rock mass was calculated using the following equation [49]:

$$
\frac{\mathrm{UCS}_{\mathrm{m}}}{\mathrm{UCS}_{\mathrm{r}}}=\left(\frac{E_{\mathrm{m}}}{E_{\mathrm{r}}}\right)^{0.7}
$$

where $\mathrm{UCS}_{\mathrm{r}}$ and $\mathrm{UCS}_{\mathrm{m}}$ are the unconfined compressive strengths of the intact rock and the rock mass, respectively.

The strength parameters of the rock mass of each geological unit in the roof and floor of the 4-2 coal seam were calculated and are shown in Table 1.

In the discrete element model, microscale strength parameters that describe the contact between particle elements were assigned. The macroscale characteristics of the rock- 
TABLE 3: Comparison of the results of simulation and empirical calculation of the self-stabilized arch height and rib spalling depth.

\begin{tabular}{lccc}
\hline Method & Simulation results & Empirical formula calculation results & Error (\%) \\
\hline Self-stabilized arch height of coal roadway roof $(\mathrm{m})$ & 2.78 & $\begin{array}{c}h_{0}=W \sqrt{3 P_{0} / 4 P_{0}+12 \sigma_{t}}=2.77[52] \\
h_{0}=\left((W / 2)+h_{\mathrm{w}}{ }^{*} \tan \left(45^{\circ}-(\varphi / 2)\right)\right) / f=2.76[52]\end{array}$ & $\begin{array}{l}0.36 \\
0=\sqrt{2 h_{\mathrm{w}}} / 4=0.57[53]\end{array}$ \\
\hline Rib spalling depth $(\mathrm{m})$ & 0.60 & $L .72$ & 5.26 \\
\hline
\end{tabular}

$h_{0}$ is the self-stabilized arch height of coal roadway roof; $W$ is the coal roadway width, and the value is $5.4 \mathrm{~m} ; P_{0}$ is the vertical earth pressure, and the value is $P_{0}=64.6 \times 0.023=1.4858 \mathrm{MPa} ; \sigma_{\mathrm{t}}$ is the tensile strength of rock mass, and the tensile strength of the rock masses was estimated to be one-tenth of the compressive strength, so the value is $0.92 \mathrm{MPa} ; \lambda$ is the lateral pressure coefficient, and the value is 0.15 ; $f$ is the rock firmness coefficient, and the value is 1.46 ; $L$ is the rib spalling depth; $h_{\mathrm{w}}$ is the coal roadway height, and the value is $2.6 \mathrm{~m}$; $\Phi$ is the internal friction angle, and the value is $36^{\circ}$.
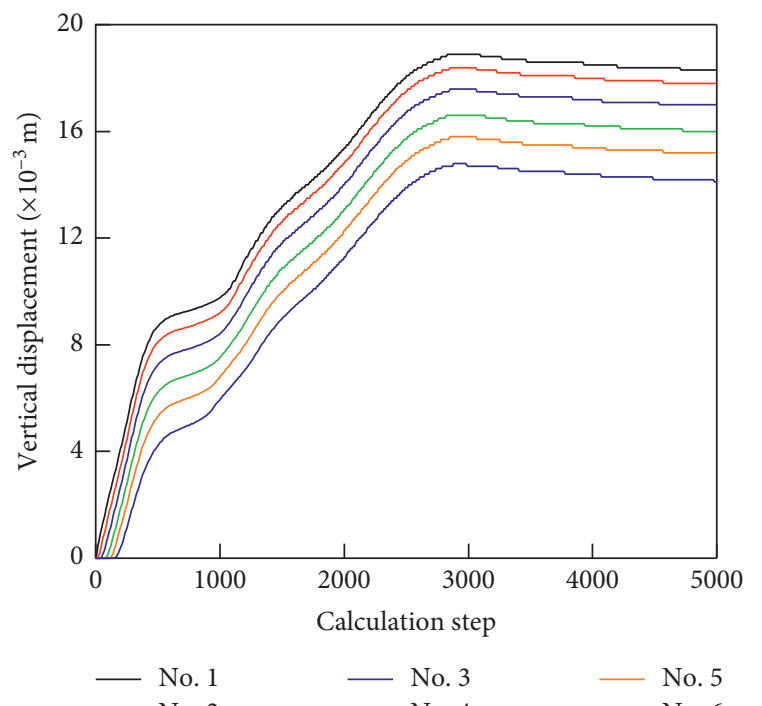

(a)

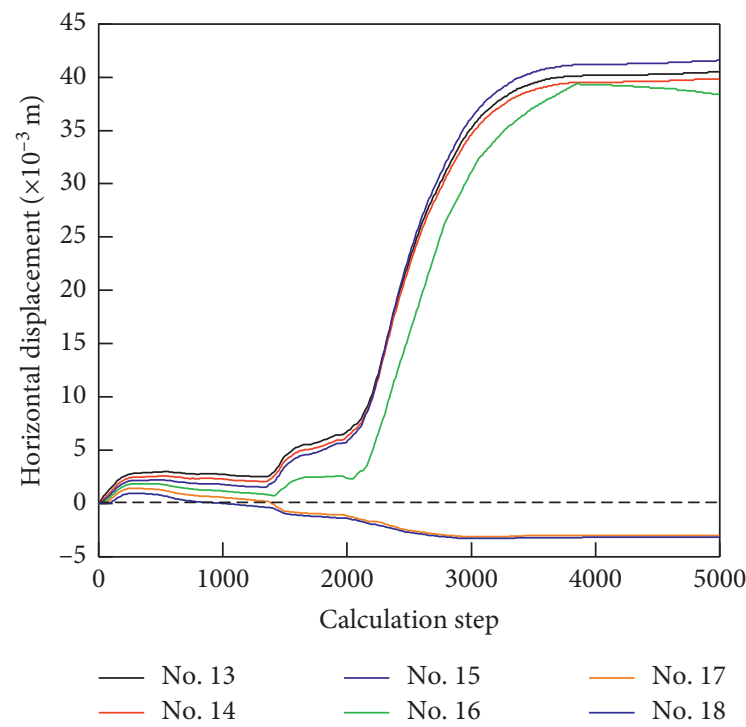

(c)

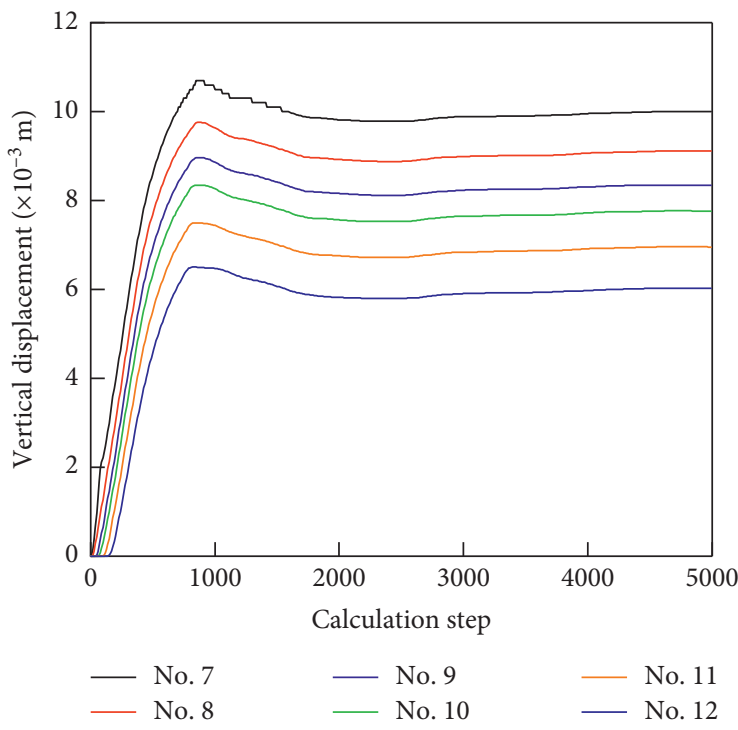

(b)

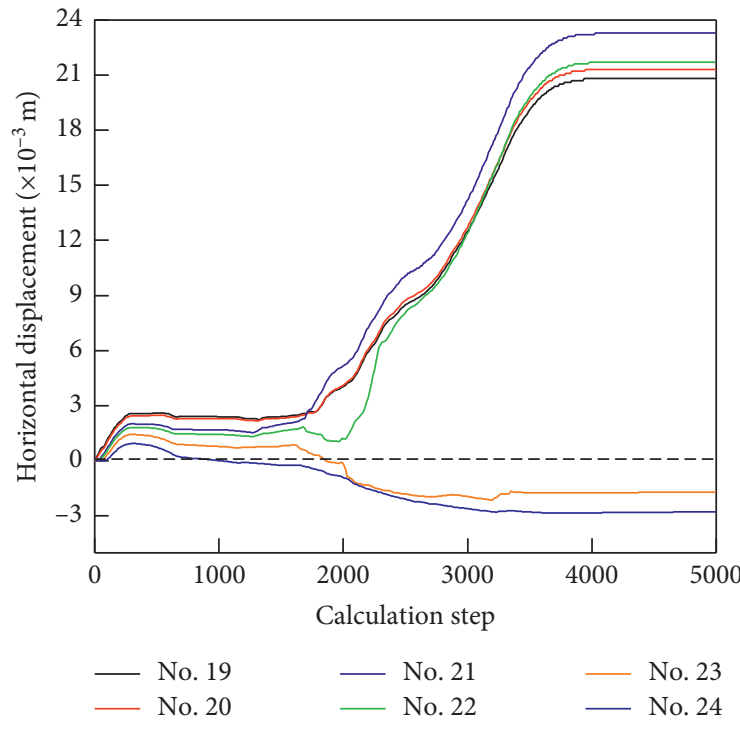

(d)

Figure 12: Displacement monitoring curves for the roadway. (a) Roof, (b) floor, (c) left wall, and (d) right wall.

soil mass were represented as the collective action of the microscale strength parameters. Therefore, it was necessary to calculate these microstrength parameters in different materials using macro-micro parameter calibration [50]. 


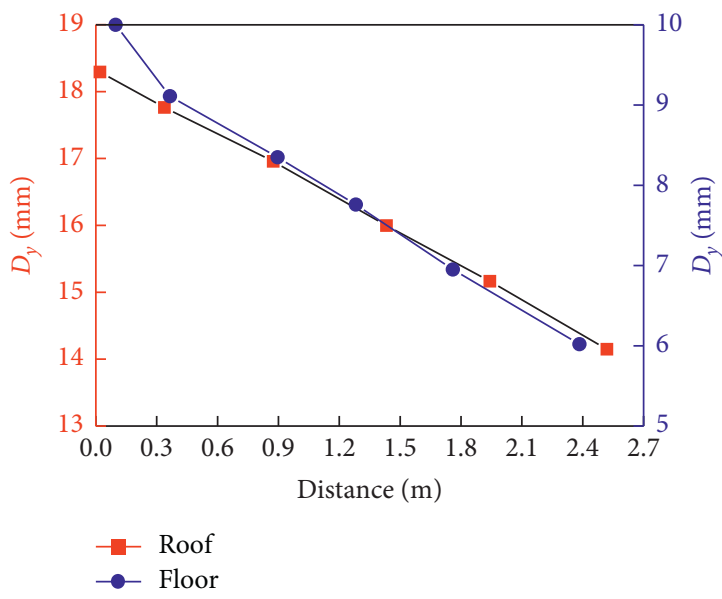

(a)

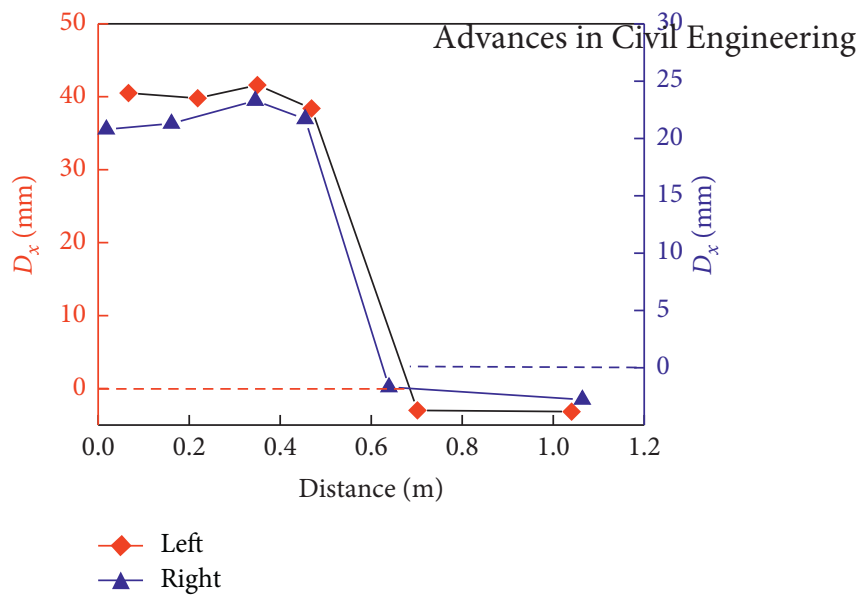

(b)

FIGURE 13: Summary of roof and floor displacements with distance from the roadway surface. (a) Vertical displacement toward the roadway $\left(D_{y}\right)$. (b) Horizontal displacement toward the roadway $\left(D_{x}\right)$.

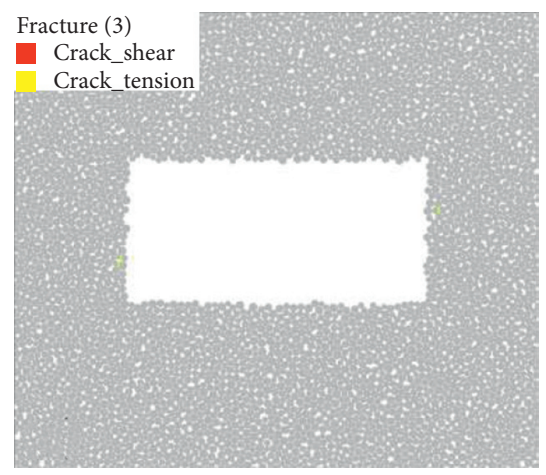

(a)

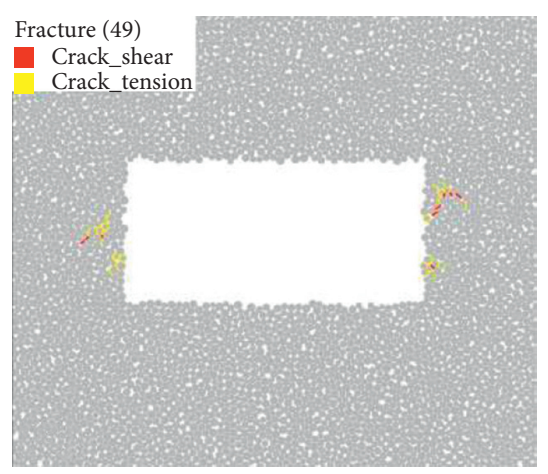

(d)

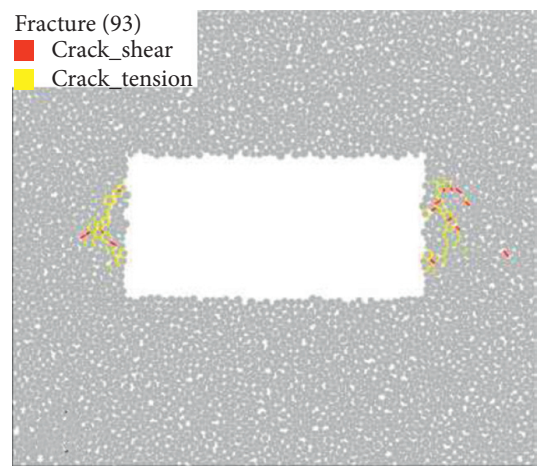

(g)

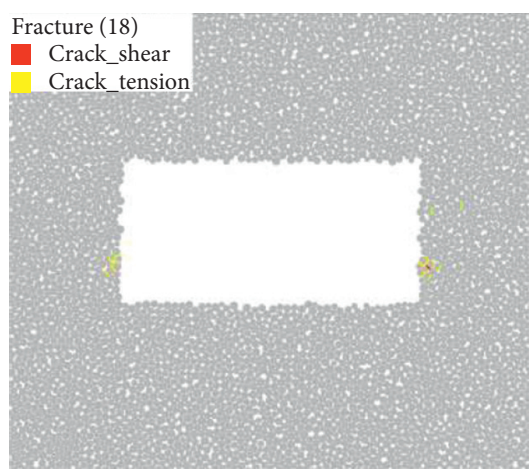

(b)

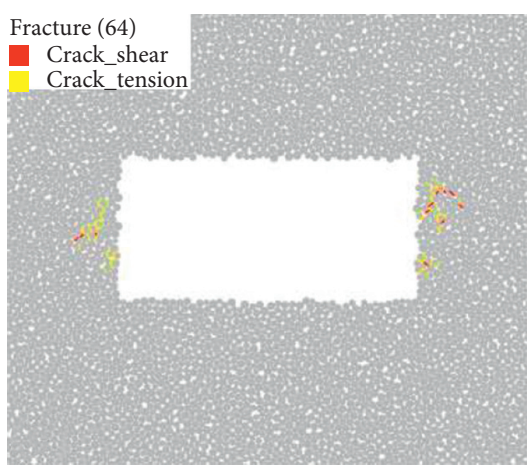

(e)

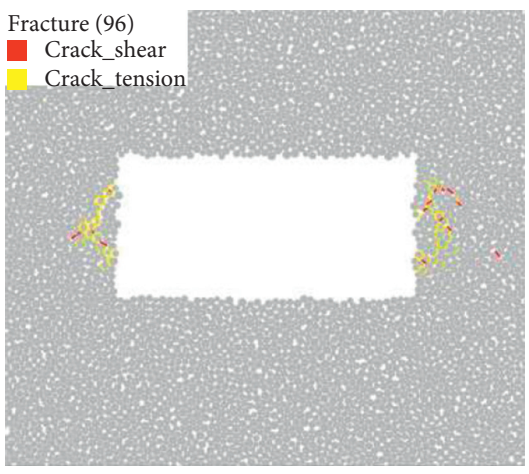

(h)

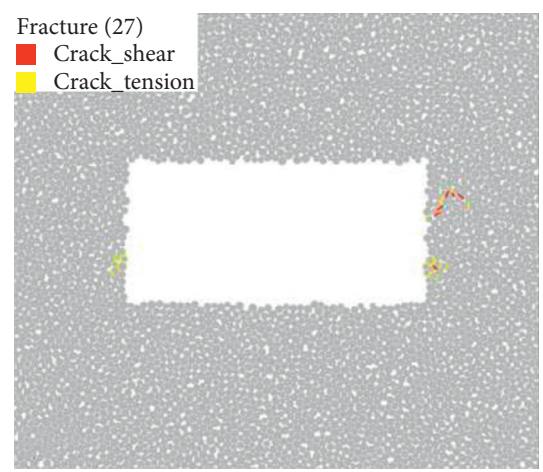

(c)

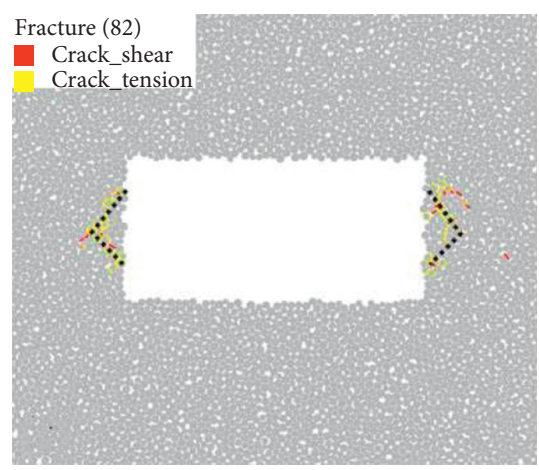

(f)

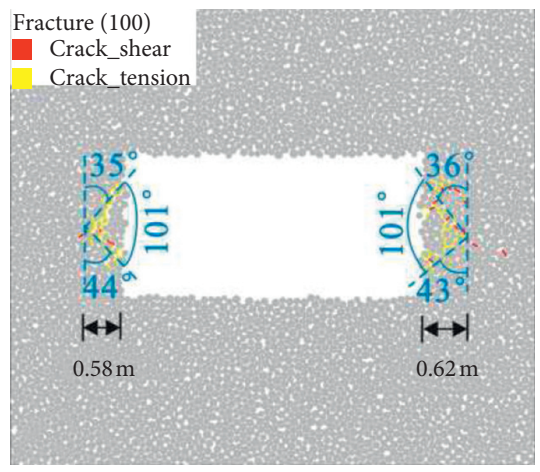

(i)

Figure 14: Evolution of damage and microcracks within the coal roadway-surrounding rock at simulation time-steps. (a) 500, (b) 1000, (c) 1300, (d) 1500, (e) 1800, (f) 2000, (g) 2500, (h) 3000, and (i) 5000. 


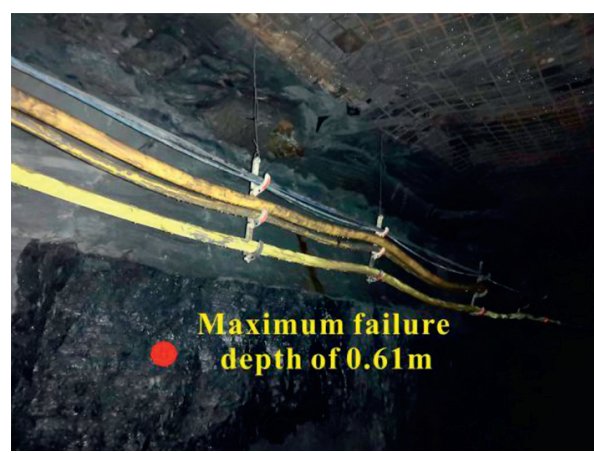

(a)

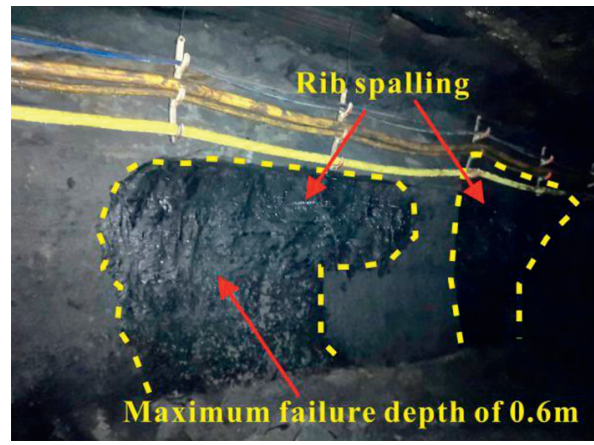

(c)

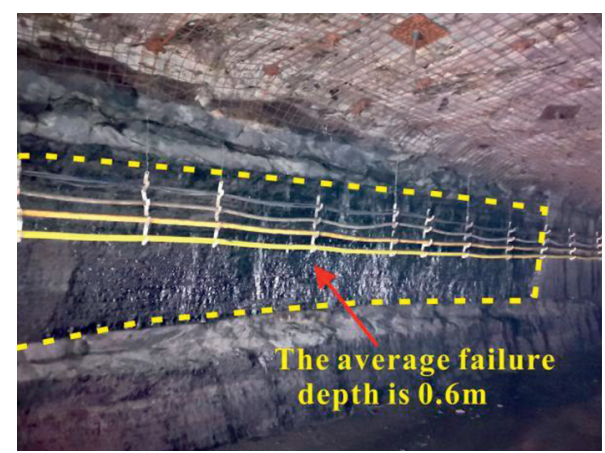

(b)

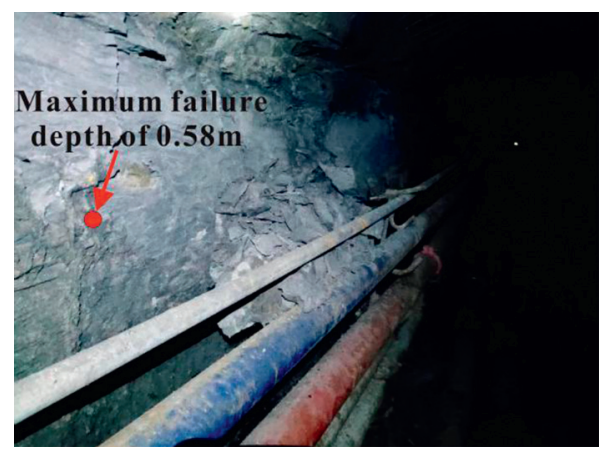

(d)

FIgURE 15: Field characteristics of coal roadway rib spalling.

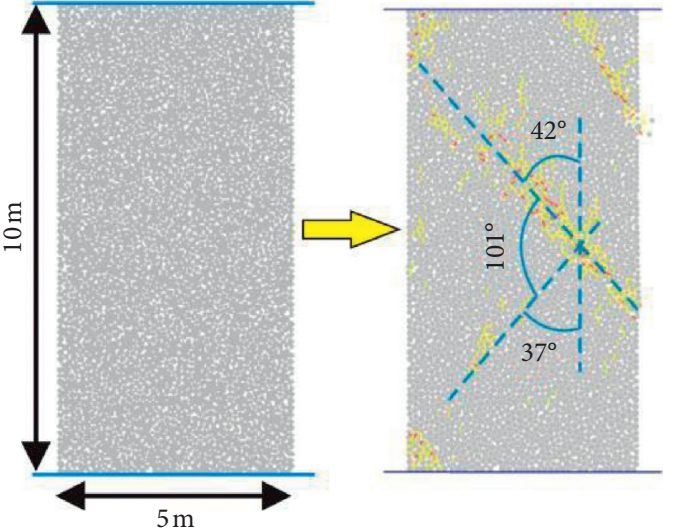

(a)

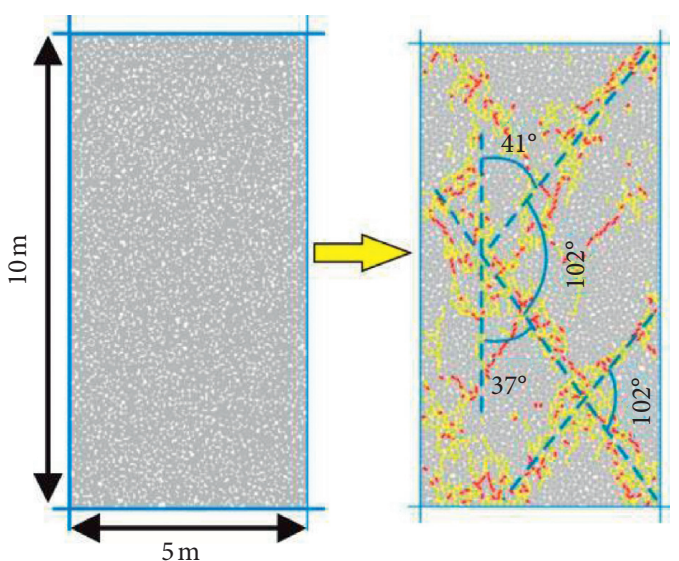

(b)

FIgURE 16: Results of (a) uniaxial compression testing and (b) biaxial loading and unloading testing of 4-2 coal.

Combined with a comprehensive analysis of the software's performance and calculation efficiency, this does not affect the deformation characteristics of the actual rock mass. Thus, to provide a more realistic simulation, the particle radius used in the model was increased appropriately. The minimum particle radius was set to $0.05 \mathrm{~m}$, and the maximum-to-minimum particle radius ratio was 1.66 [51]. The macro- and microstrength parameters of each rock mass material shown in Table 1 were calibrated using the trialand-error method (Wang and Tian [51]; Figure 5), and the corresponding microstrength parameters were obtained (Table 2). Comparing the simulated macrostrength parameters of the rock mass in Figure 5 with the macroparameters in Table 2 shows that they are very similar. This indicates that the microstrength parameters in Table 2 are reliable and can be applied to the coal roadway model. 


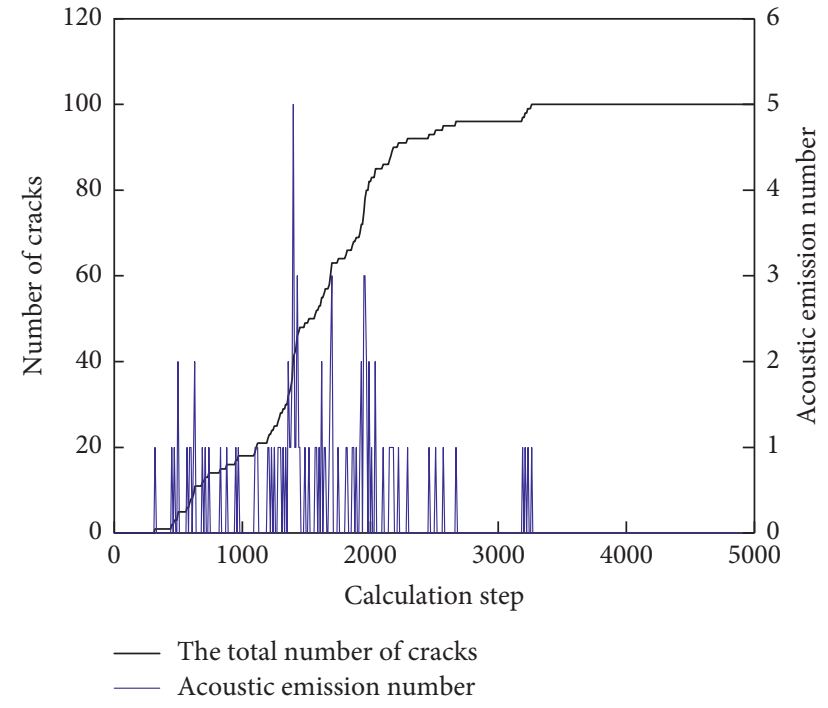

FIGURE 17: Developments in microcracks and acoustic emissions associated with deformation and failure of the coal roadway-surrounding rock.

3.3. PFC Model of the Coal Roadway. A numerical model of a cross-section of the rock surrounding the coal roadway was constructed using $\mathrm{PFC}^{2 \mathrm{D}}$ software. We assumed a plane-strain state for the roadway section and geology that followed the stratigraphy determined by drilling (Figure 6). Considering model size effects and computational efficiency [35], the size of the model was set to $20 \times 20 \mathrm{~m}$, the size of the coal roadway was $5.4 \times 2.6 \mathrm{~m}$, and the bottom of the coal roadway was close to the mudstone floor. Particles were assumed to have flexible deformation with the left, right, and bottom boundaries set as fixed and the top boundary set as a stress boundary. A vertical overburden stress of $1.495 \mathrm{MPa}$ was applied, which was consistent with the actual buried depth.

Roof mudstone was excavated during construction of the coal roadway (Figure 6), and the roof was composed of siltstone. Compared with the rigid servo mechanism (wall boundary), the pressure of the overlying rock-soil mass at the top of the model was simulated by setting flexible loading in this area to increase accuracy. The coal seam was shallow, so the horizontal additional stress was assumed to be approximately zero and the left and right boundaries were set as fixed particle boundaries. After the boundary conditions were set, gravity was applied to the model, and it was iterated until an initial equilibrium was reached. Then, construction of the model was considered complete.

After the completion of the initial model, particles at preset positions in the coal roadway were deleted. The roadway was then simulated, and the relevant indices describing the surrounding rock deformation were calculated and monitored.

\section{Results}

In the model, after excavation of the roadway, the surrounding rock deformed and showed signs of instability failure in response to excavation unloading and pressure exerted by the overlying rock-soil mass. To study the deformation and damage mechanisms of the roadway-surrounding rock, microcharacteristic indices were analyzed, including stress, displacement, and microcrack fields.

4.1. Stress Field. The roadway was relatively shallow; therefore, the horizontal additional stress was approximately zero, and the horizontal component of stress exerted by the overlying rock was small. Thus, the present study focused on the evolution of vertical stress. Vertical stress was monitored at different positions and used to produce a stress cloud diagram (Figure 7). Without support after roadway excavation, stress in the shallow parts of the surrounding rock sidewalls and in parts of the roof and floor initially decreased, while there was a gradual increase in tensile stress in the roof and floor (Figures 7(a) and 7(b)). During the middle and later stages of model evolution, the vertical stress within the surrounding rock sidewall at shallow depths was smaller than that in the original model. With increasing distance from the sidewall surface, the vertical stress first increased and then decreased, reaching a maximum at depth, with the location of sidewall stress concentration varying with time from shallow to deep. With increasing depth, the stress gradually decreased to that of the original rock. The tensile stress in the arched area of the roof and floor first increased and then decreased (Figures 7(c)-7(e)) until the 5000th time-step, when the vertical stress within the roadwaysurrounding rock was effectively stable (Figure 7(f)).

The contact force chain between particles defines the path of force transfer, while the strength characteristics that describe the contact force reflect the macroscopic mechanical characteristics of the rock-soil mass. Therefore, the contact force chain of the surrounding rock after roadway excavation was analyzed from a microscopic perspective (Figure 8). After roadway excavation and unloading, the surrounding rock particles were no longer at equilibrium. The particles moved to reach a secondary stress balance and the interparticle force chain changed (Figure 8(a)). At the beginning of excavation, the interparticle force chain was mainly vertical, and the distribution was uniform. After excavation, the contact forces in the shallow part of the roadway-surrounding rock gradually decreased, and the main contact force direction gradually changed from the original vertical direction to an inclined direction. The forces had an annular pattern, with ring-shaped contact forces being greater than radial contact forces. The unloading of the shallow parts of the roadway surface caused a gradual change in stress from the original compressive stress to tensile stress. During this time, the stress state changed from the original two-dimensional stress state to a one-dimensional stress state and, with increasing depth, the contact force gradually changed from an annular pattern to a vertical pattern, as seen in the unexcavated rock. Simultaneously, a dense area of compressive contact chains appeared in the deeper parts of the sidewall, which underwent stress concentration. The rhomboid stress within the roof, floor, and sidewall changed from the original pressure chain to a tensile chain. When the 
stress in the stress-concentration area gradually increased to the ultimate strength of the rock mass, the rock mass was gradually destroyed and cracks gradually developed. The roadway roof initially formed a self-stable arch-shaped stress area with a height of approximately $2.78 \mathrm{~m}$. The floor formed an inverted self-stable arch-shaped stress area, and the left and right sides formed a triangular self-stable stress zone with a depth of approximately $0.6 \mathrm{~m}$ which, together, formed a diamond-shaped self-stable stress area (Figure 8(b)). This is consistent with the calculations of the relevant empirical formula (Table 3). The tensile stress within the diamond gradually evolved outward through the four corners of the roadway to produce tensile stress within the area (Figure 8(c)). Thus, the release of stress from the rock surrounding the roadway led to a diamond-shaped stress distribution coupled with an X-shaped tensile stress distribution (Figure 8(c)).

Variations in the vertical and horizontal stresses within the surrounding rock after coal roadway excavation were analyzed quantitatively. We assumed that the model was symmetrical and that the shallow coal seam roadway floor was more stable than the roof. A total of 50 monitoring points at each location were assigned to sample the vertical stress within the roof and the horizontal stress on the right side of the roadway (Figure 9 (a)). The horizontal and vertical stresses were measured and analyzed at the initial time-step and 5000 steps after excavation.

Secondary stresses occurred in the surrounding rock after excavation of the roadway (Figures $9(\mathrm{~b})$ and $9(\mathrm{c})$ ). The vertical stress within the surrounding rock at a width of 6$7 \mathrm{~m}$ above the roof of the coal roadway was less than that within the original rock prior to excavation (Figure 9(b)). With increasing distance between the two sides, the vertical stress increased until it exceeded the stress of the original rock and then decreased until it approached the stress level within the rock prior to excavation. The horizontal stress of the surrounding rock was lower at $12-13 \mathrm{~m}$ in the middle of the roadway than in the original rock. However, outside these heights, the horizontal stress approached the same stress as that within the original rock. This analysis shows that, after roadway excavation, the stress in the surrounding rock was redistributed. The internal stress of surrounding rock gradually was released at a certain depth, and the stress of surrounding rock after secondary balancing was lower than that of the original rock.

4.2. Displacement Field. The deformation-related displacement of roadway-surrounding rock is the most important characteristic of roadway deformation. The evolution of the displacement field in the surrounding rock after roadway excavation was analyzed to investigate its deformation characteristics (Figure 10). With increasing time after excavation, the depth of the deformation-affected region within the surrounding rock increased, with greater deformation close to the roadway surface and lesser deformation further away (Figures 10(a)-10(e)). The displacement vector diagram of surrounding rock deformation showed that the roof strata were displaced downwards, the floor strata were displaced upwards, and shallow triangular areas on each side were displaced toward the interior of the roadway. There was shear displacement directed away from the roadway and downwards in the upper parts of these triangular areas (Figures 10(f) and 10(g)).

Qualitative analysis of the displacement field was used to monitor particle displacement at different locations within the roadway-surrounding rock (Figure 11). Additionally, the deformation degree and characteristics were studied quantitatively (Figure 12).

Deformation displacement within the roadway roof and floor strata increased with time after excavation before becoming stable (Figures 12(a) and 12(b)). However, after a rapid increase in displacement, the bottom plate showed spring-back deformation, with the displacement increasing to a peak and then decreasing slightly (Figure 12(b)). Particles in shallow positions on the left and right sides of the rock mass were displaced by deformation into the roadway space. The deformation rate was slow before time-step 1500 , increased gradually at time-step 2000, and stabilized to a constant value at time-step 3700 (Figures 12(c) and 12(d)). However, a small degree of backward-directed deformation displacement was observed in the deeper parts of the roadway sidewall, which became stable from time-step 3000 (Figures 12(c) and 12(d)).

Combined with the monitoring of particle positions, the vertical or horizontal distance from the roadway surface to a certain position in the surrounding rock was defined as the roadway surface distance (RSD). Variations in the displacements of the roof, floor, and two sidewalls were monitored by measuring the RSD after failure of the coal roadway (Figure 13). Vertical deformation of the roof and floor decreased linearly with increasing RSD. The horizontal deformation of the left and right sidewalls at different RSD positions was variable, and that of the surrounding rock did not vary greatly with increasing RSD at shallow depths $(0-0.5 \mathrm{~m})$, which was the entire deformation. However, at greater depths $(0.5-0.7 \mathrm{~m})$, the horizontal deformation of the surrounding rock decreased linearly with increasing RSD. At depths greater than $0.7 \mathrm{~m}$, the surrounding rock underwent a small reverse displacement deformation in response to shear deformation and damage.

The roof and floor of the coal roadway underwent some degree of elastic deformation after excavation, while the sidewalls underwent plastic deformation and the deep part of the plastic failure area underwent reverse shear deformation.

4.3. Microcrack Field. The evolution of the crack field was the main manifestation of the progressive failure of the surrounding rock. The initiation, propagation, aggregation, and interaction of microcracks degraded the mechanical properties of the rock mass and eventually formed macroscopic cracks. When the interparticle stress was greater than the bond strength, the bonds were destroyed and microcracks formed. Microcrack evolution during deformation of 
the surrounding rock and the damage caused by roadway excavation were simulated to analyze the progressive failure of the surrounding rock (Figure 14).

After roadway excavation, there were several tensile microcracks on the surfaces of the sidewalls (Figure 14). With increasing deformation of the surrounding rock, this group of microcracks continued to develop with a preferred orientation within the deeper parts of the surrounding rock, and several shear microcracks formed around the tensile microcracks. With the expansion and aggregation of the microcracks, a triangular group of microcracks was produced within the roadway sidewall. This group is shown by the black dotted line in Figure 14(f) and occurred when the fractures cut through the surrounding rock mass. Finally, triangular macrocracks formed on the two sidewalls from groups of microfractures, with an approximately $101^{\circ}$ angle between the sides of the triangle. The collapse angle of the coal sidewall was approximately $35^{\circ}$, and the deepest cracks on the left and right sidewalls were $0.58 \mathrm{~m}$ and $0.62 \mathrm{~m}$, respectively. The average crack depth was $0.6 \mathrm{~m}$, and no cracks formed in the roof or floor.

These results are consistent with the surrounding rock failure depth measured in the actual roadway (Figure 15), which validates the model. The analysis shows that a roof composed of medium-hard sandstone will not allow the overburden pressure to crush a shallowly buried coal roadway with a small span. However, the stress concentration shifted step-by-step to a position of fracture development; thus, a crack in the soft rock of the coal seam developed gradually and the damage was serious. Simultaneously, the vertical stress was still much greater than the horizontal stress.

According to research and analysis of the lateral stress coefficient [54], cracks most readily occur in the low-stress direction. Therefore, the coal in the sidewall was gradually broken, resulting in large displacement. Moreover, because the model is relatively uniform, the development of microfractures was basically the same on both sides. However, although the roof and floor rock masses showed deformation, there was no crack development. In reality, the roof was simply reinforced (Figures 3 and 15), and there was no damage or great displacement for a long time, which is consistent with the simulation results.

To analyze the mechanism of formation of the triangular cracks in the roadway sidewall, a uniaxial compression model and biaxial loading and unloading model were constructed (Figure 16). They used the same particle sizes as the coal seam particle model and the microstrength parameters of the coal seam (Table 2). The results show that the evolutions of failure cracks within the coal in response to the two compression types were identical. Both models produced macroscopic cross-cracks at an angle of $101^{\circ}$. The microcrack group in the roadway sidewall controlled the formation of these characteristic triangular macroscopic cracks, which formed in response to excavation unloading and overlying rock pressure. Stacey [55] and Wu et al. [56] analyzed the deformation characteristics and failure mechanism of rock surrounding a rectangular cavern excavation. They considered brittle rock conditions from the perspective of stress. Both reported that surrounding rock is more easily damaged in the direction of low stress, which is consistent with the present study.

As roadway deformation and damage progressed, microcracks continued to develop. The number of cracks and their acoustic emissions were monitored and quantitatively analyzed to characterize the fracture evolution (Figure 17). With increasing time after excavation, deformation of the surrounding rock intensified and microcrack development increased. The cracks developed rapidly between time-steps 1400 and 2200 and then ceased developing after time-step 3200. By then, the entire sidewall was unstable along the triangular macroscopic cracks. There were 100 microcracks but no more developed.

\section{Conclusions}

Deformation of and damage to the rock surrounding coalmine roadways reduce the safety, efficiency, and environmental performance of coal extraction. To investigate this issue, we conducted a case study on the 4-2 coal seam in the Xiangshuihe Coal Mine, China. Deformation of and damage to the rock surrounding a coal roadway were simulated using a $\mathrm{PFC}^{2 \mathrm{D}}$ numerical method. Microscale indices, including stress, displacement, and microcrack fields, were analyzed to monitor the deformation and damage characteristics of the roadway-surrounding rock. The results are as follows:

(1) After the excavation of the coal roadway, stress was released in the shallow parts of the surrounding rock in response to unloading. The stress pattern changed from vertical stress to circumferential stress. The regions of tensile stress migrated toward the four corners of the roadway cross-section and formed a rhomboidal stress self-stabilizing structure within an X-shaped tensile stress pattern.

(2) With increasing time after excavation, stress became concentrated in the sidewalls. When the concentrated stress exceeded the interparticle bond strength, bonds fractured and microcracks formed. These microcracks developed and merged to form macrocracks that broke the coal rock mass. Simultaneously, the combined action of overburden pressure and unloading caused shear failure in the deeper parts of the coal rock mass within the roadway sidewalls. This caused triangular-shaped peeling of the sidewalls at a depth of $0.6 \mathrm{~m}$.

(3) After roadway excavation, different parts of the surrounding rock showed different displacement and deformation characteristics. The roof and floor were slightly deformed but relatively stable. During the early stages of the model, the sidewall deviated away from the roadway in response to shearing and compression.

\section{Data Availability}

The data used to support the findings of this study are included within the article. 


\section{Conflicts of Interest}

The authors declare that there are no conflicts of interest regarding the publication of this paper.

\section{Acknowledgments}

This research was supported by the National Natural Science Foundation of China (41672279) and Scientific Research Project of Geological Research Institute for Coal Green Mining, Xi'an University of Science and Technology (MTy2019-22).

\section{References}

[1] E. Bai, W. Guo, and Y. Tan, "Negative externalities of highintensity mining and disaster prevention technology in China," Bulletin of Engineering Geology and the Environment, vol. 78, no. 7, pp. 5219-5235, 2019.

[2] X. Miao, X. Cui, J. a. Wang, and J. Xu, "The height of fractured water-conducting zone in undermined rock strata," Engineering Geology, vol. 120, no. 1-4, pp. 32-39, 2011.

[3] Q. Huang and W. He, "Research on overburden movement characteristics of large mining height working face in shallow buried thin bedrock," Energies, vol. 12, no. 21, p. 4208, 2019.

[4] Z. Meng, X. Shi, and G. Li, "Deformation, failure and permeability of coal-bearing strata during longwall mining," Engineering Geology, vol. 208, pp. 69-80, 2016.

[5] Y. Sun, J. Zuo, M. Karakus, and J. Wang, "Investigation of movement and damage of integral overburden during shallow coal seam mining," International Journal of Rock Mechanics and Mining Sciences, vol. 117, pp. 63-75, 2019.

[6] W. Wang, Y.-p. Cheng, H.-f. Wang, W. Li, and L. Wang, "Coupled disaster-causing mechanisms of strata pressure behavior and abnormal gas emissions in underground coal extraction," Environmental Earth Sciences, vol. 74, no. 9, pp. 6717-6735, 2015.

[7] H. Kang, J. Lou, F. Gao, J. Yang, and J. Li, "A physical and numerical investigation of sudden massive roof collapse during longwall coal retreat mining," International Journal of Coal Geology, vol. 188, pp. 25-36, 2018.

[8] Y. Xu, K. Pan, and H. Zhang, "Investigation of key techniques on floor roadway support under the impacts of superimposed mining: theoretical analysis and field study," Environmental Earth Sciences, vol. 78, p. 436, 2019.

[9] T. H. Yang, P. Jia, W. H. Shi, P. T. Wang, H. L. Liu, and Q. L. Yu, "Seepage-stress coupled analysis on anisotropic characteristics of the fractured rock mass around roadway," Tunnelling and Underground Space Technology, vol. 43, pp. 11-19, 2014.

[10] H. P. Kang, J. Lin, and M. J. Fan, "Investigation on support pattern of a coal mine roadway within soft rocks - a case study," International Journal of Coal Geology, vol. 140, pp. 31-40, 2015.

[11] Q. Bai, S. Tu, F. Wang, and C. Zhang, "Field and numerical investigations of gateroad system failure induced by hard roofs in a longwall top coal caving face," International Journal of Coal Geology, vol. 173, pp. 176-199, 2017.

[12] M. He, "Physical modeling of an underground roadway excavation in geologically $45^{\circ}$ inclined rock using infrared thermography," Engineering Geology, vol. 121, no. 3-4, pp. 165-176, 2011.
[13] X. Yang, J. Pang, D. Liu et al., "Deformation mechanism of roadways in deep soft rock at Hegang Xing'an coal mine," International Journal of Mining Science and Technology, vol. 23, no. 2, pp. 307-312, 2013.

[14] M. Piotr, "The impact of the physical model selection and rock mass stratification on the results of numerical calculations of the state of rock mass deformation around the roadways," Tunnelling and Underground Space Technology, vol. 50, pp. 365-375, 2015.

[15] C. Liu, Z. Yang, P. Gong et al., "Accident analysis in relation to main roof structure when longwall face advances toward a roadway: a case study," Advances in Civil Engineering, vol. 2018, Article ID 3810315, 10 pages, 2018.

[16] W. Yu, B. Pan, F. Zhang, S. Yao, and F. Liu, "Deformation characteristics and determination of optimum supporting time of alteration rock mass in deep mine," KSCE Journal of Civil Engineering, vol. 23, no. 11, pp. 4921-4932, 2019.

[17] S. C. Li, Q. Wang, H. T. Wang et al., "Model test study on surrounding rock deformation and failure mechanisms of deep roadways with thick top coal," Tunnelling and Underground Space Technology, vol. 47, pp. 52-63, 2015.

[18] Y. Xue, F. Gao, X. Liu, and X. Liang, "Permeability and pressure distribution characteristics of the roadway surrounding rock in the damaged zone of an excavation," International Journal of Mining Science and Technology, vol. 27, no. 2, pp. 211-219, 2017.

[19] J. Toraño, R. R. Díez, J. M. Rivas Cid, and M. M. C. Barciella, "FEM modeling of roadways driven in a fractured rock mass under a longwall influence," Computers and Geotechnics, vol. 29, no. 6, pp. 411-431, 2002.

[20] B. Unver and N. E. Yasitli, "Modelling of strata movement with a special reference to caving mechanism in thick seam coal mining," International Journal of Coal Geology, vol. 66, no. 4, pp. 227-252, 2006.

[21] F. Alvarez, N. Gouzalez, A. Alvarz, G. Herrera, and S. Torno, "Numerical modelling and analysis of the influence of local variation in the thickness of a coal seam on surrounding stresses: application to a practical case," International Journal of Coal Geology, vol. 79, no. 4, pp. 157-166, 2009.

[22] M. R. Islam and R. Shinjo, "Numerical simulation of stress distributions and displacements around an entry roadway with igneous intrusion and potential sources of seam gas emission of the Barapukuria coal mine, NW Bangladesh," International Journal of Coal Geology, vol. 78, no. 4, pp. 249-262, 2009.

[23] Y. Ju, Y. Wang, C. Su, D. Zhang, and Z. Ren, "Numerical analysis of the dynamic evolution of mining-induced stresses and fractures in multilayered rock strata using continuumbased discrete element methods," International Journal of Rock Mechanics and Mining Sciences, vol. 113, pp. 191-210, 2019.

[24] R. N. Singh, I. Porter, and J. Hematian, "Finite element analysis of three-way roadway junctions in longwall mining," International Journal of Coal Geology, vol. 45, no. 2-3, pp. 115-125, 2001.

[25] J. Yang, D. Wang, H. Shi, and H. Xu, "Deformation failure and countermeasures of deep tertiary extremely soft rock roadway in Liuhai coal mine," International Journal of Mining Science and Technology, vol. 25, no. 2, pp. 231-236, 2015.

[26] W. Yu and F. Liu, "Stability of close chambers surrounding rock in deep and comprehensive control technology," Advances in Civil Engineering, vol. 2018, Article ID 6275941, 18 pages, 2018.

[27] B. Duan, H. Xia, and X. Yang, "Impacts of bench blasting vibration on the stability of the surrounding rock masses of 
roadways," Tunnelling and Underground Space Technology, vol. 71, pp. 605-622, 2018.

[28] C. Liu, "Research on deep-buried roadway surrounding rock stability and control technology," Geotechnical and Geological Engineering, vol. 36, no. 6, pp. 3871-3878, 2018.

[29] Y. Yu, C. Zhu, D. Chong, Y. Liu, and S. Li, "Catastrophe mechanism and disaster countermeasure for soft rock roadway surrounding rock in Meihe mine," International Journal of Mining Science and Technology, vol. 25, no. 3, pp. 407-413, 2015.

[30] W. Yang, H. Wang, B. Lin et al., "Outburst mechanism of tunnelling through coal seams and the safety strategy by using "strong-weak" coupling circle-layers," Tunnelling and Underground Space Technology, vol. 74, pp. 107-118, 2018.

[31] J. Coggan, F. Gao, D. Stead, and D. Elmo, "Numerical modelling of the effects of weak immediate roof lithology on coal mine roadway stability," International Journal of Coal Geology, vol. 90-91, pp. 100-109, 2012.

[32] F. Gao, D. Stead, H. Kang, and Y. Wu, "Discrete element modelling of deformation and damage of a roadway driven along an unstable goaf-a case study," International Journal of Coal Geology, vol. 127, pp. 100-110, 2014.

[33] Q.-S. Bai, S.-H. Tu, C. Zhang, and D. Zhu, "Discrete element modeling of progressive failure in a wide coal roadway from water-rich roofs," International Journal of Coal Geology, vol. 167, pp. 215-229, 2016.

[34] K. Ding, S. Gu, J. Guo, D. Gu, Z. Liu, and B. Wei, "Numerical investigation on factors affecting stability of roadway surrounding rock with fractured roof," Geotechnical and Geological Engineering, vol. 37, no. 4, pp. 2373-2385, 2018.

[35] W. Liu, X. Wang, and C. Li, "Numerical study of damage evolution law of coal mine roadway by particle flow code (PFC) model," Geotechnical and Geological Engineering, vol. 37, no. 4, pp. 2883-2891, 2019.

[36] S.-Q. Yang, M. Chen, H.-W. Jing, K.-F. Chen, and B. Meng, "A case study on large deformation failure mechanism of deep soft rock roadway in Xin'An coal mine, China," Engineering Geology, vol. 217, pp. 89-101, 2017.

[37] F. Gao and D. Stead, "Discrete element modelling of cutter roof failure in coal mine roadways," International Journal of Coal Geology, vol. 116-117, pp. 158-171, 2013.

[38] N. Cristescu and I. Paraschiv, "The optimal shape of rectangular-like caverns," International Journal of Rock Mechanics and Mining Sciences \& Geomechanics Abstracts, vol. 32, no. 4, pp. 285-300, 1995.

[39] F. Gong, W. Wuxing Wu, T. Tianbin Li, and X. Xuefeng Si, "Experimental simulation and investigation of spalling failure of rectangular tunnel under different three-dimensional stress states," International Journal of Rock Mechanics and Mining Sciences, vol. 122, Article ID 104081, 2019.

[40] F.-q. Gong, W.-x. Wu, and T.-b. Li, "Simulation test of spalling failure of surrounding rock in rectangular tunnels with different height-to-width ratios," Bulletin of Engineering Geology and the Environment, vol. 79, no. 6, pp. 3207-3219, 2020.

[41] G. Wang, M. Wu, R. Wang, H. Xu, and X. Song, "Height of the mining-induced fractured zone above a coal face," Engineering Geology, vol. 216, pp. 140-152, 2017.

[42] C. Wang, C. Zhang, X. Zhao, L. Liao, and S. Zhang, "Dynamic structural evolution of overlying strata during shallow coal seam longwall mining," International Journal of Rock Mechanics and Mining Sciences, vol. 103, pp. 20-32, 2018.
[43] P. Cundall and O. Strack, "A discrete numerical model for granular assemblies,” Geotechnique, vol. 30, pp. 331-336, 1979.

[44] J. Wei, Z. Zhao, C. Xu, and Q. Wen, "Numerical investigation of landslide kinetics for the recent Mabian landslide (Sichuan, China)," Landslides, vol. 16, no. 11, pp. 2287-2298, 2019.

[45] D. O. Potyondy and P. A. Cundall, "A bonded-particle model for rock," International Journal of Rock Mechanics and Mining Sciences, vol. 41, no. 8, pp. 1329-1364, 2004.

[46] D. Yin, S. Chen, X. Liu, and H. Ma, "Simulation study on strength and failure characteristics for granite with a set of cross-joints of different lengths," Advances in Civil Engineering, vol. 2018, Article ID 2384579, 11 pages, 2018.

[47] Z. Xia, S. Chen, X. Liu, and R. Sun, "Strength characteristics and fracture evolution of rock with different shapes inclusions based on particle flow code," Geomechanics and Engineering, vol. 22, no. 5, pp. 461-473, 2020.

[48] L. Zhang and H. H. Einstein, "Using RQD to estimate the deformation modulus of rock masses," International Journal of Rock Mechanics and Mining Sciences, vol. 41, no. 2, pp. 337-341, 2004.

[49] M. Singh and K. Seshagiri Rao, "Empirical methods to estimate the strength of jointed rock masses," Engineering Geology, vol. 77, no. 1-2, pp. 127-137, 2005.

[50] C. Shi, W. Yang, J. Yang, and X. Chen, "Calibration for microscaled mechanical parameters of Granite based on a bondedparticle model with 2D Particle Flow Code," Granular Matter, vol. 38, pp. 1-13, 2019.

[51] X. Wang and L. Tian, "Mechanical and crack evolution characteristics of coal-rock under different fracture-hole conditions: a numerical study based on particle flow code," Environmental Earth Sciences, vol. 77, no. 297, pp. 1-10, 2018.

[52] Q. Huang and C. Zheng, "Theory of self-stable ring in roadway support," Chinese Journal of Rock and Soil Mechanics, vol. 37, pp. 1231-1236, 2016.

[53] Q. Huang and Y. Liu, "Ultimate self-stable arch theory in roadway support," Chinese Journal of Mining \& Safety Engineering, vol. 31, pp. 354-358, 2014.

[54] P. Jia and C. A. Tang, "Numerical study on failure mechanism of tunnel in jointed rock mass," Tunnelling and Underground Space Technology, vol. 23, no. 5, pp. 500-507, 2008.

[55] T. Stacey, "A simple extension strain criterion for fracture of brittle rock," Int J Rock Mech Min Sci Geomech Abstr, vol. 18, no. 6, pp. 469-474, 1981.

[56] W. Wu, F. Gong, and W. Yang, "Experimental simulation study of spalling in deep rectangular tunnel with plastic fine grain marble," Tunnelling and Underground Space Technology, vol. 98, Article ID 103319, 2020. 